\title{
Heavy ion formation in Titan's ionosphere: Magnetospheric introduction of free oxygen and a source of Titan's aerosols?
}

\author{
E.C. Sittler Jr., ${ }^{\text {a } *}$, A. Ali ${ }^{\text {a,b }}$, J.F. Cooper ${ }^{\text {a }}$, R.E. Hartle ${ }^{\text {a }}$, R.E. Johnson ${ }^{c}$, A.J. Coates ${ }^{d}$, D.T. Young ${ }^{\mathrm{a}}$ \\ "NASA Goddard Space Flight Center, MD, USA \\ buniversity of Maryland, College Park, MD,USA \\ "University of Virginia, Charlottesville, VA, USA \\ ${ }^{\circledR}$ Mullard Space Science Laboratory, UK \\ ESouthwest Research Instirute, San Antonio, TX, USA
}

\section{A R T ICLE I N F O}

\section{Article history:}

Received 18 February 2009

Received in revised form

16 july 2009

Accepted 21 July 2009

Available online 15 August 2009

\section{Keywords:}

Titan

Saturn's magnetosphere

Heavy negative ions

Oxygen

Aerosols

Astrobiology

\begin{abstract}
A B S T R A C T
Discovery by Cassini's plasma instrument of heavy positive and negative ions within Titan's upper atmosphere and ionosphere has advanced our understanding of ion neutral chemistry within Titan's upper atmosphere, primarily composed of molecular nitrogen, with $\sim 2.5 \%$ methane. The external energy flux transforms Titan's upper atmosphere and ionosphere into a medium rich in complex hydrocarbons, nitriles and haze patticles extending from the surface to $1200 \mathrm{~km}$ altitudes. The energy sources are solar UV, solar X-rays, Saturn's magnetospheric ions and electrons, solar wind and shocked magnetosheath ions and electrons, galactic cosmic rays (GCR) and the ablation of incident meteoritic dust from Enceladus' E-ring and interplanetary medium. Here it is proposed that the heavy atmospheric ions detected in situ by Cassini for heights $>950 \mathrm{~km}$, are the likely seed particles for aerosols detected by the Huygens probe for altitudes $<100 \mathrm{~km}$. These seed particles may be in the form of polycyclic aromatic hydrocarbons (PAH) containing both carbon and hydrogen atoms $\mathrm{C}_{n} \mathrm{H}_{x}$. There could also be hollow shells of carbon atoms, such as $\mathrm{C}_{60}$, called fullerenes which contain no hydrogen. The fullerenes may compose a significant fraction of the seed particles with PAHs contributing the rest. As shown by Cassini, the upper atmosphere is bombarded by magnetospheric plasma composed of protons, $\mathrm{H}_{2}^{+}$and water group ions. The latter provide $\mathrm{keV}$ oxygen, hydroxyl and water ions to Titan's upper atmosphere and can become trapped within the fullerene molecules and ions. Pickup keV $\mathrm{N}_{2}^{+}, \mathrm{N}^{+}$and $\mathrm{CH}_{4}^{+}$can also be implanted inside of fullerenes. Attachment of oxygen ions to PAH molecules is uncertain, but following thermalization $\mathrm{O}+$ can interact with abundant $\mathrm{CH}_{4}$ contributing to the $\mathrm{CO}$ and $\mathrm{CO}_{2}$ observed in Titan's atmosphere. If an exogenic keV $\mathrm{O}^{+}$ion is implanted into the haze particles, it could become free oxygen within those aerosols that eventually fall onto Titan's surface. The process of freeing oxygen within aerosols could be driven by cosmic ray interactions with aerosols at all heights. This process could drive pre-biotic chemistry within the descending aerosols. Cosmic ray interactions with grains at the surface, including water frost depositing on grains from cryovolcanism, would further add to abundance of trapped free oxygen. Pre-biotic chemistry could arise within surface microcosms of the composite organic-ice grains, in part driven by free oxygen in the presence of organics and any heat sources, thereby raising the astrobiological potential for microscopic equivalents of Darwin's "warm ponds" on Titan.
\end{abstract}

Published by Elsevier Ltd.

\section{Introduction}

The Voyager 1 Titan flyby on November 12,1980 showed a very complex encounter with Saturn's magnetosphere with an induced magnetotail (Ness et al, 1981) and a bite-out in the magnetospheric electron population for $E>500 \mathrm{eV}$ (Bridge et al., 1981; Hartle et al., 1982). It was also shown that the upstream plasma was composed of light and heavy ions (Hartle et al., 1982; Sittler

\footnotetext{
"Coresponding athor Tel: +13012859215; fax: +13012861433.

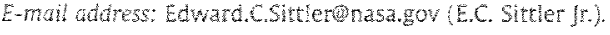

et al., 2004, 2005) and that the heavy ions $\left(\mathrm{N}^{+}\right.$or $\left.\mathrm{O}^{+}\right)$had $\mathrm{keV}$ energies. The upstream magnetic field of $\sim 5 \mathrm{nT}$ resulted in a heavy ion gyro-radii of $\sim 5000 \mathrm{~km}$, which is larger than the size of Titan. A review of Cassini plasma and field observations of Titan's interaction is given by Coates (2009a). The atmosphere detected by Voyager was primarily composed of $\mathrm{N}_{2}$. (Broadfoot et al., 1981) as predicted by Hunten (1977) and the small methane component was detected earlier by Kuiper (1944). Voyager also detected a complex suite of hydrocarbons and nitriles using the infrared spectrometer IRIS (Hanel et al., 1981, 1982). From these measurements exospheric models with $\mathrm{H}, \mathrm{H}_{2}, \mathrm{~N}_{3}, \mathrm{CH}_{4}$ and $\mathrm{N}_{2}$ were constructed (Harte et al., 1982; Sitter et al., 2004, 2005) and 
complex neutral and ion chemistry was predicted to occur in its upper atmosphere and ionosphere (Yung et al., 1984; Yung, 1987; Toublanc et al., 1995; Cravens et al., 1997). Sittler et al. (2004, 2005) also predicted that the dominant pickup ion slowing the magnetospheric plasma flow is $\mathrm{CH}_{4}^{+}$. The initial Cassini $\mathrm{T}_{\mathrm{A}}$ flyby revealed a similar interaction to that of $\mathrm{V} 1$ but with the upstream heavy ion component uniquely identified as water group ions all of which contain oxygen. They also confirmed that the dominant pickup ion was $\mathrm{CH}_{4}^{+}$with some $\mathrm{N}_{2}^{+}$(Hartle et al., 2006a,b) as predicted (Sittler et al., 2004, 2005). The ion neutral mass spectrometer (INMS) instrument on Cassini during $\mathrm{T}_{\mathrm{A}}$ encounter also detected a very complex neutral composition in Titan's upper atmosphere (Waite et al., 2005). During the T5 flyby INMS also detected a complex set of hydrocarbons which implied there was considerable ion chemistry occurring in this region (Cravens et al., 2006). The rich ion hydrocarbon chemistry extended up to ion mass $\sim 100$ amu. For later flybys when the spacecraft altitude dropped to $950 \mathrm{~km}$ Waite et al. (2007) reported the presence of benzene molecules plus heavy positive and negative ions with even higher masses. Coates et al. (2007) discovered heavy negative ions with mass $\sim 4000 \mathrm{amu}$ and higher. The number of heavy negative ions increased with decreasing altitude down to $950 \mathrm{~km}$, the minimum altitude sampled by the Cassini spacecraft. Waite et al. (2007) and Coates et al. (2007) raised the possibility that the heavy ions were polycyclic aromatic hydrocarbons or PAHs.

The above discoveries pose the question why are we seeing heavy negative ions or PAHs at all. In the studies of interstellar clouds the presence of such molecules has a long history. Herbst (1981) first posed the question that negative molecular ions could exist in molecular clouds. In that paper the high electron affinities $(>2 \mathrm{eV})$ for neutral free radicals and the large molecular size led to negative ion formation. Radiative attachment rate coefficients at cloud temperatures $\sim 10-50 \mathrm{~K}$ can be as high as the collision rate $k \sim 10^{-7} \mathrm{~cm}^{3} / \mathrm{s}$. Later, Petrie and Bohme (2007) pointed out that there was no observational evidence for negative ions within molecular clouds, though their presence would be expected at low abundances. Subsequently McCarthy et al. (2006) combined radio observations of the star IRC+10 and molecular cloud TMC- 1 and their recent laboratory measurements to detect the negative ion $\mathrm{C}_{6} \mathrm{H}^{-}$. This was later confirmed based on chemical models (Miller et al., 2007), which was then followed by detection of $\mathrm{C}_{8} \mathrm{H}^{-}$and $\mathrm{C}_{4} \mathrm{H}^{-}$in the molecular cloud TMC-1 (Brünken et al., 2007). $\mathrm{C}_{8} \mathrm{H}^{-}$ was detected within the circumstellar envelope IRC +10216 by Remijan et al. (2007). Sakai et al. (2007) detected $\mathrm{C}_{6} \mathrm{H}^{-}$within a low-mass star-forming region of $L 1527$ and then later Sakai et al. (2008) reported the detection of $\mathrm{C}_{4} \mathrm{H}^{-}$near the low-mass Class 0 protostar IRAS $04368+2557$. The anion $\mathrm{C}_{3} \mathrm{~N}^{-}$was discovered within the interstellar medium (ISM) by Thaddeus et al. (2008). Then Herbst and Osamura (2008) performed quantum mechanical model calculations confirming on theoretical grounds the likely presence of the detected ion $\mathrm{C}_{n} \mathrm{H}^{-}$. They calculated high radiative attachment coefficients $>5 \times 10^{-8} \mathrm{~cm}^{3} / \mathrm{s}$ that were similar to those measured by Miller et al. (2007). Relevant to the observations reported here, the observed negative ions $\mathrm{C}_{72} \mathrm{H}^{-}$have high carbon to hydrogen ratios $(n \geq 3$ with $n=3$ having the lowest rate coefficient and $n=8$ the highest rate coefficient (Herbst and Osamura, 2008).

In the case of Titan the ethynyl radical $\left(\mathrm{C}_{2} \mathrm{H}\right)$ and benzene radical $\mathrm{C}_{6} \mathrm{H}_{5}$ (phenyl) can be important for the polymerization of PAHs (Goulay and Leone, 2006). At Titan the Cassini INMS instrument detected both acetylene (Waite et al., 2005) and benzene (Waite et al. 2007; Vuitton et al, 2009a) and their radicals $\mathrm{C}_{2} \mathrm{H}$ (i.e. indirectly detected by Vuiton et al., 2009b) and $\mathrm{C}_{5} \mathrm{H}_{5}$ or phenyl by vuitton et al. (2009a). Vuitton et al. (2007) also reported the detection of numerous hydrocarbons such as polyynes $\left(\mathrm{C}_{4} \mathrm{H}_{2}, \mathrm{C}_{6} \mathrm{H}_{2}, \mathrm{C}_{8} \mathrm{H}_{2}\right)$, possible detection of methylpolyynes $\left(\mathrm{CH}_{3} \mathrm{C}_{4} \mathrm{H}, \mathrm{CH}_{3} \mathrm{C}_{6} \mathrm{H}\right)$ and benzene $\left(\mathrm{C}_{6} \mathrm{H}_{6}\right)$. They also detected nitrogen bearing molecules cyanopolyynes $\left(\mathrm{HC}_{3} \mathrm{~N}, \mathrm{HC}_{5} \mathrm{~N}\right), \mathrm{NH}_{3}$. methanimine $\left(\mathrm{CH}_{2} \mathrm{NH}\right)$, nitriles $\left(\mathrm{C}_{2} \mathrm{H}_{3} \mathrm{CN}, \mathrm{C}_{2} \mathrm{H}_{5} \mathrm{CN}\right)$ and possibly methylcyanopolyynes $\left(\mathrm{CH}_{3} \mathrm{C}_{3} \mathrm{~N}, \mathrm{CH}_{3} \mathrm{C}_{5} \mathrm{~N}\right)$. Nitrogen bearing molecules can contribute to $\mathrm{PAH}$ formation and could thus be an important constituent of aerosols. The reader is referred to a comprehensive review article on PAH polymerization by Allamandola et al. (1989) the details of which are beyond the scope of this paper. The combination of recent detections of negative ions within molecular clouds and recent detections by Cassini of heavy negative ions at Titan suggests that there might be a connection between heavy negative ions and PAHs and/or fullerene formations. This does not mean that neutrals and positive ions do not also play an important role in the growth of heavier molecules since reaction rates for ion-neutral collision, involving either positive or negative ions, tend to be much faster than those for neutral-neutral collisions (e.g., Waite et al., 2007). However, as noted above, the radicals $\mathrm{C}_{2} \mathrm{H}$ and $\mathrm{C}_{5} \mathrm{H}_{5}$ are probably also present at Titan, in which case growth of fullerenes and PAHs can also occur via neutral-neutral collisions (Goulay and Leone, 2006; Mebel et al., 2008; Bettens and Herbst, 1995). It is also true that acetylene and benzene can both lead to the growth of fullerenes and PAHs depending upon the chemical pathway taken (see Bettens and Herbst, 1995). The introduction of keV oxygen ions from Saturn's magnetosphere and their possible incorporation into fullerenes and possibly PAHs as discussed here, adds another dimension with strong exobiological implications. The present paper explores the implications of these two potentially related discoveries, upper atmospheric formation of the heavy negative ions and bombardment by keV oxygen ions for chemistry of Titan's atmosphere and surface.

\section{Observations}

\subsection{Observations of heavy ions by Cassini}

We begin this section by reviewing the relevant plasma observations of Titan's upper atmosphere and ionosphere made by the Cassini plasma spectrometer (CAPS) and ion neutral mass spectrometer (INMS) instruments. The first discovery of extremely heavy negative ions within Titan's ionosphere was made by the high time resolution observations of the CAPS electron spectrometer (ELS) during the $T_{A}$ encounter and revealed a surprising population of heavy negative ions. These ions were subsequently observed on 15 other Titan encounters, and were analyzed by Coates et al. (2007) and initially reported by Waite et al. (2007). In all cases the negative ions observed near closest approach, were narrowly confined to the spacecraft ram direction, and contained distinct energy peaks (see Figs. 1 and 2 from Coates et al., 2007). During the spacecraft's flight through Titan's relatively cold ionosphere the spacecraft motion, $\sim 6 \mathrm{~km} / \mathrm{s}$, provides an effective mass spectrometer feature for cold ionospheric ions. The conversion factor from ram energy to mass for singly charged ions at $6.0 \mathrm{~km} / \mathrm{s}$ is $m_{\mathrm{amu}}=5.32 E_{\text {a }}$ (Coates et al., 2007).

The CAPS instrument also has an ion beam spectrometer (IBS) primarily designed to measure high Mach plasma flows in the solar wind. But this instrument also provides good measurements of the positive ion component of Titan's ionosphere which, during these encounters, also appear as a high Mach flow in the spacecraft reference frame. This instrument has detected heavy positive ions (Waite et al., 2007). The mass of the positive ions extends up to several hundred amu but the detected ions are significantly less massive than the detected negative ions. Abundances of both the positive and negative ions peak at the lowest altitudes encountered $(\sim 950 \mathrm{~km})$. 
For $T_{A}$ the observed maximum energy of the negative ions was $\sim 60 \mathrm{eV}$, corresponding to an ion mass/charge $m / q \sim 320 \mathrm{amu} / \mathrm{q}$. During other encounters, such as T16, the ion masses were as high as 10,000 amu/q as seen in Fig. 1 adpated from Coates et al. (2007). On various other encounters the ions were observed in rough mass groups at 10-30, 30-50, 50-80, 80-110, 110-200, (200-500, $500+$ ) amu/q (Coates et al., 2007) because neither the ELS or IBS measure mass, but rather mass/charge. It was argued that these ions may in fact be multiply charged in this region of high electron density; therefore the actual mass could be up to five times higher. Such large highly charged ions provide seeds for forming aerosols (Coates et al., 2007, Waite et al, 2007). This relationship between mass and charge state is strongly tied to the assumed size of the ions with the following relationships. Waite et al. (2007) used $\varphi \sim-2.5 \mathrm{kT} / \mathrm{e} \sim 0.027 \mathrm{~V}(T \sim 125 \mathrm{~K})$ based on the surface potential for a small dust grain with its corresponding charge $Q=4 \pi \varepsilon_{0} a$ a $\exp \left(-a / \lambda_{D}\right)\left(\varepsilon_{0}\right.$ is permittivity of free space, $a$ is grain's radius and $\lambda_{D}$ is the Debye length). As discussed below, if the heavy ions are fullerenes, then the mean ion radius is estimated to be $r_{A} \sim 12 \AA$ giving $Q \sim 1$ and a maximum mass $<10,000 \mathrm{amu}$. If one uses for the heavy ions PAHs, then $r_{A} \sim 60 \hat{A}$ is possible so that $Q \sim 5$ is estimated and very large ion masses become possible. Therefore, whether the heavy negative ions are fullerenes or PAHs becomes an important discriminator with regard to their true size.

As discussed in Coates et al. (2009b), negative ions were not anticipated this high in Titan's atmosphere and were not included in pre-Cassini chemical schemes (e.g., Wilson and Atreya, 2004) so that new chemical models are required. As noted earlier, ionneutral collisions have high collision cross-sections, which in the case of the heavy ions approach the geometric cross-section (Waite et al., 2007). This allows such ions to grow rapidly in mass and size resulting in heavy ion formation. An important parameter in this growth process is the charge state. In case of negative ions this depends on the electron affinity of the molecule which as discussed below favors fullerenes.

The relationship between these ions and the heavy positive ion population was discussed by Waite et al. $(2007,2008)$. They suggested that nitrogen and methane in Titan's high atmosphere would be acted on by sunlight and magnetospheric particles forming heavier but relatively simple species by dissociation and ionization processes. Eventually this could lead to the growth of benzene and the other heavier ions detected by IBS up to $\sim 350 \mathrm{amu} / \mathrm{q}$ (note that the upper limit could be set by the IBS detection threshold and even heavier positive ions could exist in substantial amounts). The growth process would continue to form heavier positive and negative ions. They suggested that these may be the tholins originally postulated by Sagan and Khare (1979). With continued growth these molecules could become large enough to be called aerosols and drift down towards Titan's surface. This chain of processes, initiated by magnetospheric interactions at the top of the atmosphere eventually affects the surface composition of Titan. This idea was supported by the extensive observations of negative ions by Coates et al. (2007).

Recently, further analysis of negative ion signatures has extended the number of encounters where negative ions were observed to 22 during Cassini's prime mission (Coates et al., $2009 b$ ). This allows a systematic study showing that the higher mass negative ions are observed preferentially as follows: (1) at low altitudes, with the highest mass $(\sim 10,000 \mathrm{amu} / \mathrm{q})$ at Cassini's lowest altitude of $950 \mathrm{~km},(2)$ at high Titan latitudes and (3) in the region of the terminator. On the basis of these results, Coates et al. (2009b) suggested that the formation of high mass negative ions is more efficient, or that destruction is less efficient when solar flux is highly attenuated. Coates et al. (2007) also suggested the possible ion identifications: (1) $10-20 \mathrm{amu} / \mathrm{q} \mathrm{CN}^{-}, \mathrm{NH}_{2}^{-}$and $\mathrm{O}^{-}$; (2) $30-50 \mathrm{amu} / \mathrm{q} \mathrm{NCN}^{-}$, $\mathrm{HNCN}^{-1}$ and $\mathrm{C}_{3} \mathrm{H}^{-}$; (3) $50-80 \mathrm{amu} / \mathrm{q} \mathrm{C}_{5} \mathrm{H}_{5}^{-}$. $\mathrm{C}_{6} \mathrm{H}^{-}, \mathrm{C}_{6} \mathrm{H}_{5}^{-}$; and (4) mass groups 80-110, 110-200, 200-500 and

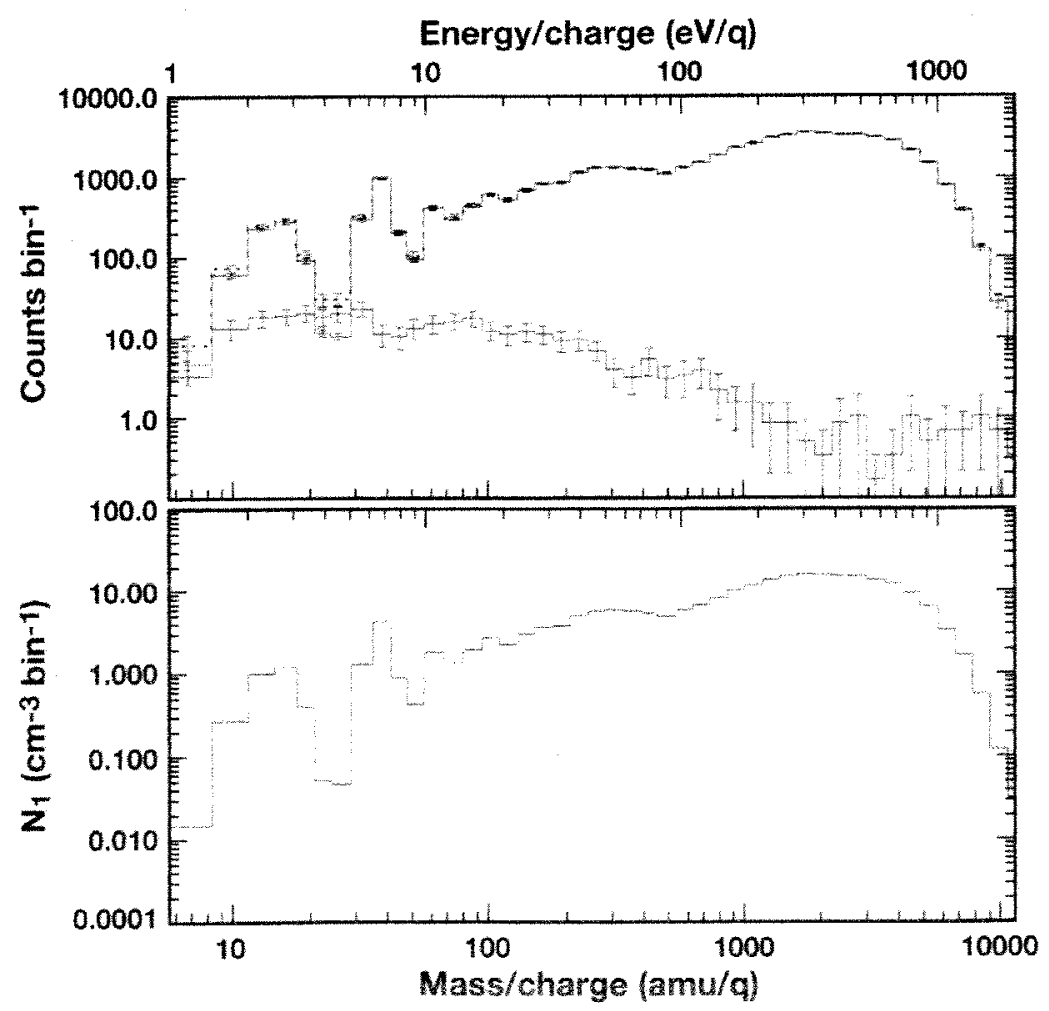

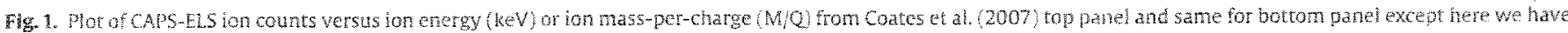
ion densiry. 
500-10,000 as polyynes, high order nitriles, PAHs and cyan aromatics. Nitrogen substitution PAHs are another possibility, but may not be stable in the UV environment of Titan's upper atmosphere. They may, however be stable in the haze layer of Titan's stratosphere at altitudes below $400 \mathrm{~km}$ (e.g., Ricca et al., 2001). More recently, Vuitton et al. (2009b) using a photochemical model have identified peaks in the CAPS-ELS mass spectrum at $22 \pm 4 \mathrm{amu} / \mathrm{q}$ as $\mathrm{CN}^{-} / \mathrm{C}_{2} \mathrm{H}^{-}, 44 \pm 8 \mathrm{amu} / \mathrm{q}$ as $\mathrm{C}_{3} \mathrm{~N}^{-} / \mathrm{C}_{4} \mathrm{H}^{-}$and $82 \pm 14 \mathrm{amu} / \mathrm{q}$ as $\mathrm{C}_{5} \mathrm{~N}^{-}$. Most noteworthy is $\mathrm{C}_{2} \mathrm{H}^{-}$which is more abundant than $\mathrm{CN}^{-}$below $850 \mathrm{~km}$ altitude in their model calculations. The fact that the ionization ratio for $\mathrm{C}_{2} \mathrm{H}^{-} / \mathrm{C}_{2} \mathrm{H}$ is $\sim 2.4 \times 10^{-5}$ in their model shows that the free radical $\mathrm{C}_{2} \mathrm{H}$ is likely present in Titan's upper atmosphere.

\subsection{The formation of fullerenes and PAHs in Titan's upper atmosphere}

As discussed in the papers by Coates et al. (2007, 2009b), and Waite et al. $(2007,2008)$ the heavy positive and negative ions could be evidence for the formation of PAHs $\left(\mathrm{C}_{2 n_{3}} \mathrm{H}_{x}\right)$ in Titan's ionosphere. The heavier ions are observed at lower altitudes with $950 \mathrm{~km}$ being the lowest altitude sampled by the Cassini spacecraft. Vuitton et al. (2009a) have presented evidence of benzene in Titan's upper atmosphere with molar fractions $\sim 10^{-6}$ at $950 \mathrm{~km}$ altitude and levels higher than expected (see Lavvas et al., 2008a,b). Acetylene $\mathrm{C}_{2} \mathrm{H}_{2}$ has a molar abundance $\sim 10^{-3}$ at $1100 \mathrm{~km}$ (Vuitton et al., 2009b) and is more abundant than benzene (also see Shemansky et al., 2005; Waite et al., 2007). For atmospheric temperature like that at Titan, $T \sim 150 \mathrm{~K}$, one expects acetylene and benzene to lead to the formation of fullerenes and $\mathrm{PAHs}$, respectively.

Laboratory measurements at much higher temperatures can produce fullerenes using low pressure benzene-oxygen flames (Gerhardt et al., 1987; Richter and Howard, 2000). PAHs can be formed in the laboratory using low pressure acetylene-oxygen flames (see Gerhardt et al., 1987). As discussed below at lower temperatures $T<300 \mathrm{~K}$ the reverse is true. There is a lot of free energy within Titan's upper atmosphere from bombarding highenergy photons (UV/EUV and X-rays) and magnetospheric charged particles. This high-energy input results in high thermal electron temperatures $T_{\mathrm{ec}} \sim 1000 \mathrm{~K}$ (Wahlund et al., 2005) and hot suprathermal photoelectrons $T_{\mathrm{er}} \sim 20,000 \mathrm{~K}$ (Hartle et al., 2006a,b; Coates, 2009a). But, the ion-neutral and neutral-neutral collisions that lead to the growth of the heavy ions occur for $T \sim 150 \mathrm{~K}$. The high electron temperatures may affect ion charge state and formation of radicals. The above measurements were also made in oxygen flames, but Titan is essentially devoid of oxygen except for low abundances of $\mathrm{CO}, \mathrm{CO}_{2}$ and $\mathrm{H}_{2} \mathrm{O}$ within Titan's atmosphere. Therefore, we feel these earlier laboratory measurements are not applicable to Titan.

More relevant to the observations at Titan fullerene and $\mathrm{PAH}$ formation occur under space environmental conditions within interstellar and circumstellar environments that more closely resemble Titan's upper atmosphere (e.g., Bohme, 1992). X-ray crystallography measurements have shown fullerenes to be hollow carbon cages (see Fig. 2) made of 60 carbon atoms $C_{60}$ (720 amu) which have spherical shape or 70 carbon atoms $C_{70}$ (840 amu) with ellipsoidal shape (Kratschmer, et al. 1990). The measured inner diameters are $\sim 7 \AA$ with effective mass density $\rho_{\mathrm{F}} \sim 1.8 \mathrm{gm} / \mathrm{cm}^{3}$ (i.e., mean radius $r \sim 5.4 \mathrm{~A}$ for $\rho \sim 2.25 \mathrm{gm} / \mathrm{cm}^{3}$ for outer shell made of carbon with thickness $\sim 3.4 \AA$ ). This should be compared to aerosol radii $r_{A}-12.5 \mathrm{~nm}$ estimated by Liang et at. (2007). Note, the $r_{\AA}-260 \mathrm{~nm}$ estimated by Waite et al. (2007) was an over estimate (Wate, 2008, private communication ${ }_{j}$. Both $C_{60}$ and $C_{70}$ are known to be very stable (Kroto et al., 1985; Kroto et al.,
Chemical Reviews, 1992, Vol. 92, No. 71499
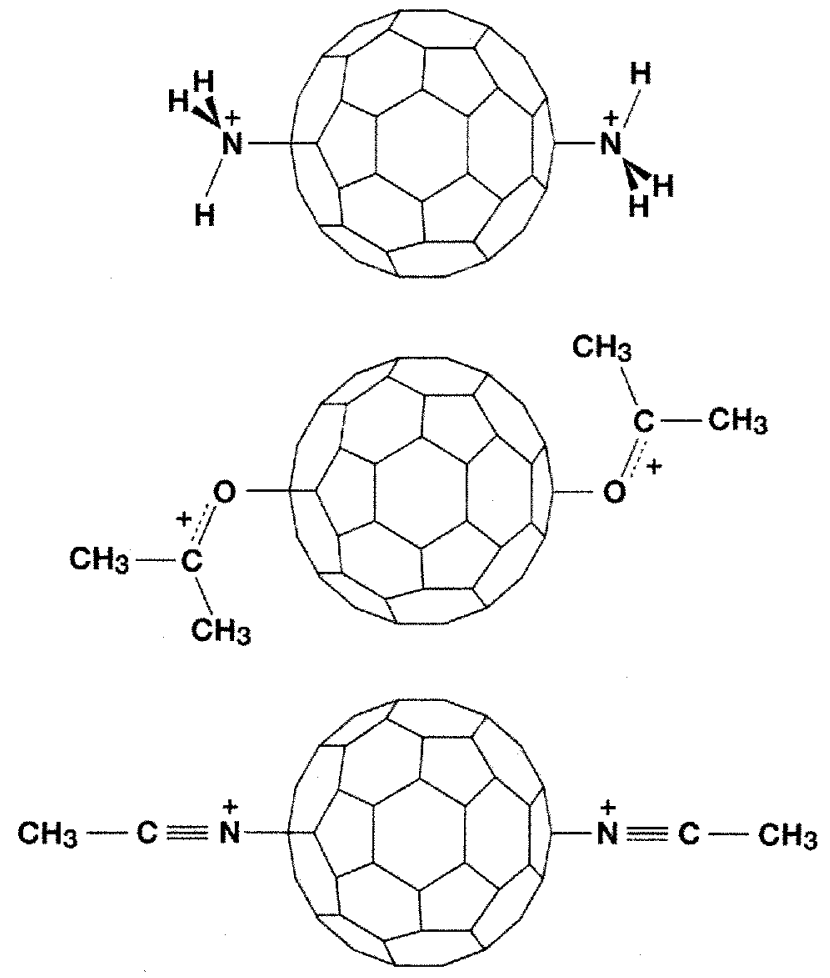

Fig. 2. Shows cage structure for $C_{60}$ fullerenes as described in the review article by Bohme (1992). (Three examples of proposed "winged" structures for double adducts of the type $\mathrm{C}_{60}(\mathrm{XH})_{2}^{2+}$ where $\mathrm{XH}=\mathrm{NH}_{3},\left(\mathrm{CH}_{3}\right)_{2} \mathrm{CO}$, and $\mathrm{CH}_{3} \mathrm{CN}$.

1991) and are found to be the end product of forest fires (Richter and Howard, 2000; Calcote et al., 1990; Frencklach, 2002). The main difference between fullerenes and PAHs is that the former has no hydrogen $\left(C_{60}\right)$, while PAHs have hydrogen $\left(\mathrm{C}_{2 n} \mathrm{H}_{x}\right)$.

There is a "zipper" mechanism often discussed with regard to the formation of fullerenes. Hunter et al. (1994) gave one explanation on how this "zipper" mechanism works. They based their conclusions on laboratory measurements where they used a laser vaporization of graphite source which produced ionized carbon chains and rings. The cluster ions of carbon were injected at different energies into a Helium buffer gas where they were thermalized. They use a quadrupole mass spectrometer to select cluster ion products of different mass. Their measurements showed that fullerenes were produced from intermediate monocyclic, bicyclic and tricyclic (i.e., polycyclic) carbon rings. Then from low frequency vibration modes and strain relief of the larger cyclic rings and the resulting spiraling of polyyne chains, fullerenes form. These measurements also showed that the activation energy $-2.4 \mathrm{eV}$ for fullerene formation were unexpectedly low. In the papers by Thaddeus $(1994,1995)$ the argument is made that PAHs are not likely to be the dominant path to heavy molecules or aerosols and grains within diffuse molecular clouds, but rather fullerenes which have their origins from long carbon chains which then fold into polycyclic rings and then fullerenes. Thaddeus $\left(1994,1995\right.$ ) then go on to say that fullerenes from $C^{+}$ insertion reactions with $H, O, N, S$, etc, can then grow into larger "amorphous carbon" organic polymers. There is experimental evidence of clustering of fullerenes $\left(C_{60}\right)_{n}$ with $n<147$ observed in the laboratory by Martin et al. (1996) with major peaks in their mass spectrum at $n=13$ and 55 . Whether such ciustering within Titan's atmosphere can occur must await further laboratory measurements more characteristic of Titan's atmosphere. 
If heavy negative ions observed by Cassini are fullerenes, then they should prefer a negative charge. Laboratory measurements by Yang et al. (1987), Wang et al. (1991) and Wang et al. (2005) have shown $C_{60}$ to have high electron affinity $(2.6-2.9 \mathrm{eV})$, and since electron attachment for $\mathrm{PAH}$ s occur for electron affinities $>1 \mathrm{eV}$ (Moustefaoui et al., 1998), fullerene negative ions are allowed. But, in some cases fullerenes can be stripped of electrons to form +1 and +2 cations (Weiske et al., 1991). The measurements by Moustefaoui et al. (1998) were made at relatively high electron temperatures $\sim 300 \mathrm{~K}$ or more and that it is difficult to achieve lower electron temperatures $T \sim 150 \mathrm{~K}$ in the laboratory (Goulay et al., 2004). Titan's upper atmosphere and ionosphere are relatively cold with neutral and ion temperatures $\sim 150 \mathrm{~K}$ (Waite et al., 2005, 2007), but the electron temperatures can be quite hot with thermal electron temperatures $T_{e, c} \sim 1000 \mathrm{~K}$ (Wahlund et al. 2005) and hot component photoelectron temperatures $T_{\text {e.h }} \sim 20,000 \mathrm{~K}$ (Hartle et al., 2006a,b; Coates, 2009a; Cravens et al., 2009). It is important to note that electron attachment to fullerenes $C_{60}$ and $C_{70}$ has an exponential temperature dependence that increases rapidly for $T_{e}>500 \mathrm{~K}$ with relatively high rate coefficient $\beta_{\mathrm{e}} \sim 3 \times 10^{-8} \mathrm{~cm}^{3} / \mathrm{s}$ (Smith et al, 1993; Spanel and Smith, 1994; Spanal and Smith, 1995; Jaffike et al., 1994) at $T_{\mathrm{ec}} \sim 1000 \mathrm{~K}$ (Wahlund et al, 2005), so electron attachment to fullerenes seems allowed. More recently, Ågren et al. (2009) did a more systematic study of Titan's ionosphere and determined the dayside peak densities to be $2500-3500 \mathrm{el} / \mathrm{cm}^{3}$ and the nightside peak densities to be $400-1000 \mathrm{el} / \mathrm{cm}^{3}$. The ionospheric peak electron temperature is rather constant near $350-700 \mathrm{~K}$. The lower electron temperatures given in this report will give lower electron attachment rates for $C_{60} \sim 10^{-8} \mathrm{~cm}^{3} / \mathrm{s}$ and for electron densities $N_{\mathrm{ec}} \sim 3000 \mathrm{el} / \mathrm{cm}^{3}$ on the dayside attachment time scales are $\sim 9 \mathrm{~h}$, while for nightside with $N_{\mathrm{ec}} \sim 1000 \mathrm{el} / \mathrm{cm}^{3}$ electron attachment time scales $\sim 27 \mathrm{~h}$. If one uses the temperature for photoelectrons with $T_{\mathrm{eh}} \sim 20,000 \mathrm{~K}$ and $N_{\mathrm{eh}} \sim 10 \mathrm{el} / \mathrm{cm}^{3}$ (Hartle et al., 2006b for TA) the fullerene attachment rate is estimated

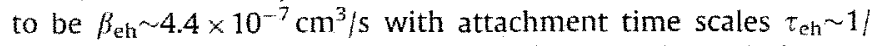
$\left(N_{\mathrm{eh}} \beta_{\mathrm{eh}}\right) \sim 2.6$ days which are longer than the thermal electron attachment time scales.

In case of positive ions recombination time scales are $\alpha \sim 10^{-5}$, $T_{\mathrm{ec}}^{0.6} \sim 2 \times 10^{-7} \mathrm{~cm}^{3} / \mathrm{s}$ for $T_{\mathrm{cc}} \sim 700 \mathrm{~K}$ are relatively fast $\tau_{\mathrm{ze}} \sim 1-2 \mathrm{~h}$ (Cravens et al., 2006). Photoionization rates for atoms and smaller molecules, for which the ionization potentials are $\geq 10 \mathrm{eV}$, are typically $\sim 10^{8}$ s (see Sittler et al., 2008 ) or time scales $\sim 3 \mathrm{yr}$. Borucki et al. (2006) considered photoemission rates for embryo aerosols ( $3 \AA$ ) within Titan's lower atmosphere for heights less than $400 \mathrm{~km}$. Fullerene sizes are similar to the embryo aerosols considered by Borucki et al. (2006) and have ionization potentials $\sim 7.07 \mathrm{eV}$ (Bettens and Herbst, 1995), so photoemission rates for fullerenes and their clusters are expected to be higher than those for atomic and molecular ions. Their calculations do show that when in shadow photo-detachment of electrons from negative ions (i.e., fullerenes) will be much lower and thus more likely to retain their negative charge. This is supported by the CAPS-ELS observations reported by Coates et al. (2009b) where heavy negative ions are more important near terminator local times at Titan. Estimation of the actual charge state of fullerenes requires development of a complex model similar to that by Borucki et al. (2006), including photo-detachment rates, ion-neutral and ionion charge transfer rates and is thus beyond the scope of this paper. But, the relatively high electron affinities and electron attachment rates are consistent with negative charge states for fullerenes. This will be the subject of future work.

Ionization of the upper atmosphere comes in part from solar UV. magnetospheric electrons and $X$-ray photons but also arises from bombardment by hot keV magnetospheric heavy oxygen ions (Hartle et al., 2006a,b,c) and energetic protons and oxygen ions (Mitchell et al., 2005 and Cravens et al., 2008). The energetic protons and $>10 \mathrm{keV}$ oxygen ions can penetrate below $950 \mathrm{~km}$ (Luna et al., 2003; Cravens et al., 2008; Hartle et al., 2006c) where the heavy positive and negative ions are observed by Cassini (Coates et al., 2007; Waite et al., 2007). Galactic cosmic ray protons (Capone et al., 1983; Molina-Cuberos et al., 1999) penetrate much more deeply and dominate ionization in the lower atmosphere. Ionization layers at altitudes $\sim 700 \mathrm{~km}$ can form due to meteoritic dust impacts as shown by Molina-Cuberos et al. (2001). lonization layers $\sim 500 \mathrm{~km}$ were observed by the Cassini radio science experiment by Kliore et al. (2008). The key to the formation of fullerenes and PAHs within this environment is then the combination of relatively high methane abundance and the high-energy radiation input to the atmosphere.

\subsection{Role of oxygen input from magnetosphere and micrometeorites}

The role of oxygen becomes particularly significant for astrobiology if fullerene formation occurs. Oxygen is an important ingredient of amino acids and other chemical compounds necessary for evolution of life, and exothermic oxidation of nutrients is critical to biochemical processes. Major abundance of free oxygen in Titan's highly reducing atmosphere is highly unlikely (Raulin and Owen, 2003), but the bound molecular form is found in trace species such as CO at the $60 \mathrm{ppm}$ level in Titan's atmosphere as discovered by Lutz et al. (1983). This was later followed by the discovery of $\mathrm{CO}_{2}$ in Titan's atmosphere at the $1.5 \mathrm{ppb}$ level by Samuelson et al. (1983), who showed that water entry from above may be required in order to explain the presence $\mathrm{CO}_{2}$ having a relatively short lifetime $\sim 5 \times 10^{4} \mathrm{yr}$. In both cases the oxygen is locked up in the $\mathrm{CO}$ and $\mathrm{CO}_{2}$ which are fairly stable molecules $\left(\mathrm{CO} \rightarrow \mathrm{C}+\mathrm{O}+11.17 \mathrm{eV} ; \mathrm{CO}_{2} \rightarrow \mathrm{CO}+\mathrm{O}+5.46 \mathrm{eV} ; \mathrm{CO}_{2} \rightarrow \mathrm{C}+\mathrm{O}+\mathrm{O}+\right.$ $16.63 \mathrm{eV}$ ). It was argued that the $\mathrm{CO}$ was probably primordial in origin but the recent model results by Hörst et al. (2008) showed that this was not required due to the entry of keV oxygen ions to Titan's upper atmosphere (Hartle et al., 2006a,b).

oxygen can be introduced into Titan's upper atmosphere by entry and ablation of micrometeorites containing water molecules (Samuelson et al., 1983). Models of Titan's atmosphere after the discoveries of $\mathrm{CO}$ and $\mathrm{CO}_{2}$ required an inward flux of oxygen as summarized in Table 1 . In the case of Yung et al. (1984) they required oxygen influx $\sim 6.1 \times 10^{5} \mathrm{O}$ atoms $/ \mathrm{cm}^{2} / \mathrm{s}$, while that by Toublanc et al. (1995) used a downward flux $\sim 1.5 \times 10^{6} \mathrm{O}$ atoms $/ \mathrm{cm}^{2} / \mathrm{s}$. The mechanism of meteoroid ablation in Titan's upper atmosphere was initially suggested by Ip (1990) for the case of water ice particles and stony particles. Then English et al. (1996) proposed a micrometeorite ablation model for water

Table 1

Summary of oxygen source for Titan's upper atmosphere.

\begin{tabular}{|c|c|c|}
\hline & Oxyzen source & $\begin{array}{l}\text { In flux rate } \\
\left(0 / \mathrm{cm}^{2} / \mathrm{s}\right)\end{array}$ \\
\hline Lutz et al. (1983) & CO discovery $-60 \mathrm{ppm}$ & \\
\hline $\begin{array}{l}\text { Samueison et al. } \\
\text { (1983) }\end{array}$ & $\begin{array}{l}\mathrm{CO}_{2} \text { dicovery } 1.5 \text { ppo } 110 \text { mbars } \mathrm{E} \\
\text { ring \& Meteoricand meteoric dust as } \\
\text { source of } \mathrm{O}\end{array}$ & $8.1 \times 10^{5}$ \\
\hline Yung a $a\} .(1984)$ & Based on $\mathrm{CO}$ and $\mathrm{CO}_{2}$ chemistry & $6.5 \times 10^{5}$ \\
\hline $\begin{array}{l}\text { Toublanc et al. } \\
\text { (1995) }\end{array}$ & Chemical model with $\mathrm{CO}$ \&and $\mathrm{CO}_{2}$ & $1.5 \times 10^{6}$ \\
\hline English et al. (1996) & Microneteorite dust abiation & $3 \times 10^{6}$ \\
\hline Lara et al. (1996) & $\begin{array}{l}\mathrm{CO} \text { \&and } \mathrm{CO}_{2} \text { model baset on Engish } \\
\text { et al. (1996) }\end{array}$ & $3 \times 10^{6}$ \\
\hline $\begin{array}{l}\text { Coustenis et al. } \\
\text { (1998) }\end{array}$ & Discovery of $\mathrm{H}_{2} \mathrm{O}-8 \mathrm{ppb} 0400 \mathrm{~km}$ & $0.8-2.8 \times 10^{6}$ \\
\hline Hartie et al. $(2006 a$ & Ta keV magnetosphento & $1.8 \times 10^{6}$ \\
\hline Hartse et al. (2006b) & Ta keV magnetospheric $\mathrm{O}^{*}$ & $1.1 \times 10^{6}$ \\
\hline
\end{tabular}


entry with peak deposition rate at $\sim 700 \mathrm{~km}$ altitude. Their model showed peak flux $\sim 3 \times 10^{6} \mathrm{~mol} / \mathrm{cm}^{2} / \mathrm{s}$. The discovery of water in Titan's atmosphere by Coustenis et al. (1998) with mole fraction $\sim 8 \mathrm{ppb}$ at $400 \mathrm{~km}$ altitude ended any doubts about the presence of water products in Titan's upper atmosphere. The Coustenis et al. (1998) results inferred an influx rate of $0.8-2.8 \times 10^{6} \mathrm{~mol} / \mathrm{cm}^{2} / \mathrm{s}$.

Cassini results continue to build the case for oxygen and water sources in the upper atmosphere. Hartle et al. (2006a,b) presented the first observational evidence of magnetospheric keV oxygen ions into Titan's upper atmosphere with an estimated influx rate $\sim 1.1 \times 10^{6} \mathrm{O}$ atoms $/ \mathrm{cm}^{2} / \mathrm{s}$ at the exobase. The presence of negative oxygen ions in Titan's upper atmosphere can be inferred by the mass 16 peak in Fig. 1 from T16 adapted from Coates et al. (2007). This might be expected due to the high electro negativity of oxygen atoms. This is also suggested by Cravens et al. (2008). although Vuitton et al. (2009b) based on T40 heavy negative ion measurements argue against a significant presence of $\mathrm{O}^{-}$. When vuitton et al. (2009b) included the influx of oxygen $\sim 10^{5} \mathrm{O} / \mathrm{cm}^{2} / \mathrm{s}$, which is $5 \%$ of "typical" of that reported by Cravens et al. (2008) for T5 and $10 \%$ of that reported by Hartle et al. (2006a,b) $\sim 10^{6} \mathrm{O} / \mathrm{cm}^{2} / \mathrm{s}$ for $\mathrm{TA}$, the $\mathrm{O}^{-}$densities increased from a maximum of $10^{-6} \mathrm{O}^{-} / \mathrm{cm}^{3}$ at $1100 \mathrm{~km}$ altitude to $4 \times 10^{-3} \mathrm{O}^{-} / \mathrm{cm}^{3}$ at $1100 \mathrm{~km}$. If a more typical value of the influx is used and the uncertainties in the cross-sections are accounted for one could argue that elimination of $\mathrm{O}^{-}$from the CAPS-ELS mass spectrum cannot yet be made. It is also important to note that there are times when no heavy ions are present in the upstream magnetospheric flow and times when it dominates the upstream flow (Sittler et al., 2009) and therefore one must consider such complications when interpreting negative ion mass spectra for specific Titan flybys (i.e., T16 vs. T40).

The CDA observations of E-ring dust particles by Srama et al. (2006) within Saturn's outer magnetosphere allows one to estimate an influx rate of water molecules into Titan's upper atmosphere $\sim 2.5 \times 10^{5}$ water $\mathrm{mol} / \mathrm{cm}^{2} / \mathrm{s}$ at the exobase. In the case of magnetospheric oxygen ions and E-ring dust particles, the source of the water and oxygen can be traced back to Enceladus (Johnson et al., 2005; Sittler et al., 2006).

\subsection{Trapping of free oxygen and hydroxyl ions in seed particles}

Laboratory experiments show that $C_{60}^{+} 6-16 \mathrm{keV}$ ions (lab frame kinetic energy) can trap lower mass target gas atoms inside the fullerenes. Magnetospheric $\mathrm{keV} \mathrm{O}^{+}$ions incident upon Titan's upper atmosphere can be implanted and become trapped within Titan's fullerenes. The laboratory measurements are quite extensive for fullerene trapping of target noble gases such as $\mathrm{He}, \mathrm{Ne}$, $\mathrm{Ar}$, Xe and Kr. Weiske et al. (1991) found that $\mathrm{C}_{60}+\mathrm{He} \rightarrow \mathrm{C}_{x} \mathrm{He}$ $(46<x<60)$ for He target gas at $C_{60}^{+}$incident energy (product fractional percentage) of $6 \mathrm{keV}(30 \%), 8 \mathrm{keV}(34 \%), 10 \mathrm{keV}(14 \%)$ and $16 \mathrm{keV}(<1 \%)$. The equivalent center of mass energies for incident He ions would be $33,44,56$ and $89 \mathrm{eV}$, respectively. For incident $\mathrm{O}^{+}$ions the equivalent center of mass energy would range from 132 to $356 \mathrm{eV}$. As $\mathrm{keV} \mathrm{O}^{*}$ ions lose energy within Titan's upper atmosphere (e.g., Shah et al., 2009) and their energies drop below $400 \mathrm{eV}$ they can become trapped in fullerenes with higher probability. This trapping will occur deeper in the atmosphere as the $\mathrm{O}^{+}$incident energy increases (i.e., ion penetration into atmosphere increases as the ion initital energy increases). In case of Argon center of mass energies used were $\sim 450 \mathrm{eV}$, while for $\mathrm{Kr}$ center of mass energies were $\sim 1230 \mathrm{eV}$ (Caldwell et al., 1991, 1992). The higher center of mass energies can cause fragmentation of the fullerene with ejection of carbon atoms. Higher center of mass collisions up to $1 \mathrm{keV}$ for $\mathrm{O}^{+}$have yet to be done. In some cases more than one He atom was implanted into a fullerene.
Caldwell et al. (1991, 1992) did similar experiments using $\mathrm{He}, \mathrm{Ne}$ and $\mathrm{Ar}$ and found end products $\mathrm{C}_{60} \mathrm{He}^{+}, \mathrm{C}_{60} \mathrm{He}_{2}^{+}, \mathrm{C}_{70} \mathrm{He}^{+}, \mathrm{C}_{84} \mathrm{He}^{+}$, $\mathrm{C}_{55} \mathrm{Ne}^{+}$and $\mathrm{C}_{55} \mathrm{Ar}^{+}$. Xe and $\mathrm{Kr}$ were not captured due to their larger size as compared to the space inside fullerenes. These results are consistent with X-ray crystallography measurements of fullerene dimensions and size within their hollow cage.

From these laboratory results two mechanisms are invoked. Mechanism 1 is the "low pressure limit" for which the ion is injected directly into the fullerene, while mechanism 2 is in the "high pressure limit" for a collision induced fracture of the carbon cage occurring first and then being followed by atom capture as an ion complex. The first mechanism could apply at Titan for direct injection of oxygen ion into the fullerene. Although, most of the oxygen ions will form $\mathrm{CO}$ and $\mathrm{CO}_{2}$ once thermalized. the direct implantation mechanism does not have this problem. The capture cross-section (fullerene geometric cross-section $\left.\sigma_{\mathrm{F}} \sim \pi\right)_{\mathrm{F}}^{2} \sim 4 \times 10^{-15} \mathrm{~cm}^{2}$ ) is quite large. Results of Coates et al. (2007) for mean negative ion mass $\sim 4000$ amu (i.e., embryo aerosol) give $4000 / 720-6$ cages, radius $r_{\mathrm{A}} \sim 7 \AA$ or larger and geometric cross-section $\sigma_{\mathrm{A}} \sim \pi r_{\mathrm{A}}^{2} \sim 1.5 \times 10^{-14} \mathrm{~cm}^{2}$.

Trapping of oxygen ions inside the fullerenes provides a stable means of oxygen conveyance within the upper atmosphere which is ultimately delivered to the surface. Complex chemistry of prebiotic and even biotic interest could occur as oxygen-laden aerosol particulates precipitate to any surface hot spots associated with local cryovolcanism (Sotin et al., 2005; Lopes et al., 2007; Nelson et al., 2008) and where liquid water might be present near the surface.

In the modeling by Michael and Johnson (2005) and Michael et al. (2005), the energy input into Titan's upper atmosphere by $\mathrm{keV}$ magnetospheric heavy ions, the heavy ions tended to dominate the energy input to Titan's upper atmosphere. They assumed the ions were directed down into Titan's atmosphere. This was the case since for $V 1$ the convective electric field pointed radially away from Saturn so that pickup ions on the Saturn side of Titan would be accelerated into Titan's upper atmosphere. For T5 the electric field is pointed southward so pickup ions are accelerated into Titan's northern hemisphere. In cases when Titan is above the magnetospheric current sheet the pickup ions will be accelerated into Titan's southern hemisphere. They found the pickup ions tended to dominate the energy input to Titan's upper atmosphere relative to the magnetospheric input. Therefore, implantation of $\mathrm{N}^{+}, \mathrm{N}_{2}^{+}$and $\mathrm{CH}_{4}^{+}$pickup ions into the fullerenes could also be occurring at levels comparable to oxygen input rates.

\subsection{Transport to lower atmosphere and surface as aerosols}

Estimates of the mass flux of the heavy ions observed in Titan's ionosphere downward to the surface can address whether these ions might account for the aerosols observed by Tomasko et al. (2005) using the Huygens DISR imaging system. In principle we can also estimate the potential surface delivery rate of oxygen bound in fullerenes due to aerosol transport. As stated earlier the heavy negative ion density increased with depth in the atmosphere with the highest masses and number densities at the minimum altitude $950 \mathrm{~km}$ probed by Cassini (Coates et al., 2007). Such increases likely continue to lower altitudes and perhaps ultimately to maximum densities of aerosol cloud layers 100-200 km or lower (de kok et al., 2007) above the surface. Lavvas et al. (2008a,b) developed a photochemical model of Titan's atmosphere which extended from the surface to the upper atmosphere $z \sim 1400 \mathrm{~km}$ altitude. In these papers the size distribution of the haze particles was derived with height using a 10 diffusive transport code with source and sink terms for the size distribution of particles. The calculations determined the size 
distribution of the aerosols at different heights with peak number densities $\sim 100$ part $/ \mathrm{cm}^{3}$ and size $r_{\mathrm{A}} \sim 10^{-3} \mu \mathrm{m}$ at $950 \mathrm{~km}$. Lavvas et al. $(2008 \mathrm{~b}$ ) give particle mass $\sim 5000 \mathrm{amu}$, very close to that observed by Coates et al. (2007) at $950 \mathrm{~km}$. Near the surface these latter authors estimate particles sizes $\sim 0.5 \mu \mathrm{m}$ with number densities $\sim 7$ part $/ \mathrm{cm}^{3}$.

Borucki and Whitten (2008) and built on earlier models by Borucki et al. (1987, 2006), modeled haze particle distributions for heights less than $150 \mathrm{~km}$. They assumed three mass fluxes $4 \times 10^{-14} \mathrm{~kg} / \mathrm{m}^{2} / \mathrm{s}$ for case B, $4 \times 10^{-13} \mathrm{~kg} / \mathrm{m}^{2} / \mathrm{s}$ for case $C$, and $10^{-12} \mathrm{~kg} / \mathrm{m}^{2} / \mathrm{s}$ for case $\mathrm{D}$, also assume mass flux conservation, and do not use diffusion terms which are essentially unknown. Using Stokes Equation from Roe et al. (2002), they estimated fall velocity $\sim 5 \times 10^{-6} \mathrm{~m} / \mathrm{s}$ for case $B$ and $\sim 4 \times 10^{-5} \mathrm{~m} / \mathrm{s}$ for case $D$. The particle sizes were $r \sim 0.45 \mu \mathrm{m}$ for case $B, 0.95 \mu \mathrm{m}$ for case $C$ and $r \sim 1.3 \mu \mathrm{m}$ for case $D$. The particle abundances were $\sim 6 \times 10^{6}$ part $/ \mathrm{m}^{3} \sim 6$ part $/ \mathrm{cm}^{3}$, which are very close to that estimated by Lavvas et al. (2008b). In this paper we estimate a simplified fall velocity applicable to the higher altitudes probed by Cassini which includes simple frictional drag from molecular collisions on the heavy ions. The expression is as follows:

$V_{\text {drift }}=\frac{M_{\text {seed }} g(z)}{N_{\mathrm{N}_{2}} M_{\mathrm{N}_{2}} w_{\mathrm{N}_{2}} \sigma_{\text {seed }}}$

with

$\sigma_{\text {seed } j}=\pi r_{\text {seed }}^{2}$

where $M_{\text {sead }}$ is the mass of the heavy ion observed by Coates et al. (2007) and we refer to as seed particles for the aerosols (ot embryo aerosols), $g(z)$ is the local acceleration of gravity which is a function of height $z, N_{N_{3}}$ is the number density of $N_{2}$ molecules, $M_{N_{2}}=28$ amu is the mass of $N_{2}, w_{N_{2}}$ is the thermal speed of the $\mathrm{N}_{2}$ molecules and $\sigma_{\text {seed }}$ is the geometric cross-section of the seed particles plus that of the $\mathrm{N}_{2}$ molecules. We use this expression to estimate the heavy ion fall speed at $950 \mathrm{~km}$ which one finds to be $\sim 10 \mathrm{~m} / \mathrm{s}$ for fullerenes and $\sim 0.4 \mathrm{~m} / \mathrm{s}$ for PAHs (i.e., both with same $M / Q$ see previous discussions about ion charge state and crosssectional size).

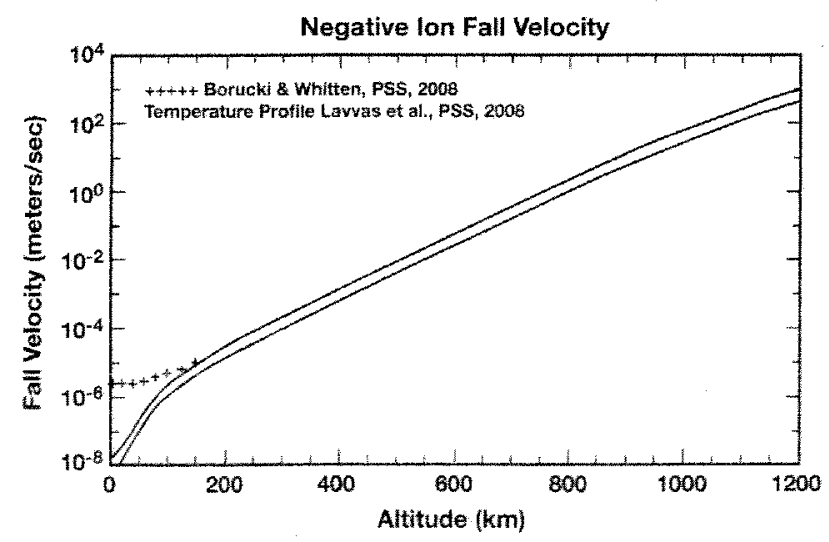

Fig. 3. Plot of aerosol fall velocity (m/s) versus altitude based on our smplifed expression in Eqs. (1) and (2) from above $950 \mathrm{~km}$ down to the surface. Two curves are shown for particles mass 4000 and 40,000 amu (top curve). If particles are spherical they will ful faster as they grow, but if more planaf then thei hal velocity independent of particle mass for a given height. We atso show the estimates by Borucki and Whitten (2008a,b) for altitudes $<150 \mathrm{~km}$. Our estimate is less than Boruck and Whitten (2008d, as wonld be expeted since the particte

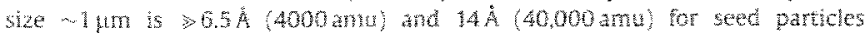
observed above 950 kn altude our exprestion for spherich 1 hm shed particics would yield fal velocites several orders of magnitudes grater than that shown here for 40,000 amu particles.
We show in Fig. 3 the fall speed of the haze particles as a function of height for different assumed haze particles mass ( 4000 and $40,000 \mathrm{amu}$ ). In reality, as the haze particles fall they will grow in size and tend to fall faster as they become more massive except for the increase in frictional drag due to the increased cross-sections and atmospheric $\mathrm{N}_{2}$ density with depth. Looking at Eqs. (1) and (2), heavier spherical ions will fall faster linearly with particle radius $r$ (i.e., $M_{\mathrm{p}} \sim(4 \pi / 3) p r^{3}$ and $\sigma_{\mathrm{p}} \sim \pi r^{2}$ ). Fluffy or planar particles will fall at a speed independent of particle mass at a given height. Assuming fullerenes as the primary aerosol component, and taking the ion number densities with mean mass $\sim 4000$ amu of the heavy negative ions we estimate at $950 \mathrm{~km}$ altitude a downward mass flux $\Phi \sim 2.7 \times 10^{-14} \mathrm{~kg} / \mathrm{m}^{2} / \mathrm{s}$. This flux is smaller than the lower limit $\Phi \sim 4 \times 10^{-14} \mathrm{~kg} / \mathrm{m}^{2} / \mathrm{s}$ used by Borucki and Whitten $(2008 \mathrm{a}, \mathrm{b})$ and constrained by Tomasko et al.'s (2005) aerosol observations but considering uncertainties identical. If the mass density flux increases below $950 \mathrm{~km}$ as expected, then the heavy ions observed above $950 \mathrm{~km}$ may be sufficient to account for all the aerosols observed by Tomasko et al. (2005) near the surface. If one uses the mass flux rate $\sim 4 \times 10^{-14} \mathrm{~kg} / \mathrm{m}^{2} / \mathrm{s}$ and a surface mass density $\sim 420 \mathrm{~kg} / \mathrm{m}^{3}$ it will take $\sim 300$ Myrs to accumulate an aerosol depth of one meter $\left(420 \mathrm{~kg} / \mathrm{m}^{2}\right)$ uniformly distributed around the globe. If one uses the higher mass fluxes of Borucki and Whitten $(2008 \mathrm{a}, \mathrm{b})$ the accumulation times could be as short as $\sim 10$ Myrs.

\subsection{Loss of ionospheric ions to Titan's surface}

We now consider the effect of heavy negative ion drift and formation of an ambipolar electric field. We have ignored the role of heavy positive ions $N_{\text {Heavy } j}$ since they are less abundant than the dominant ionospheric ions $N_{\text {ION }, j}$. Then assuming the seed particles are negative and imposing the charge neutrality condition

$\sum_{j} N_{\text {seed } j} Q_{\text {seed } i}+N_{e}=\sum_{j} N_{\text {lON, } j}+\sum N_{\text {Heavy } j} Q_{\text {Heavy } j}$

$N_{e} \cong \sum_{j} N_{\mathrm{ION}, j}$

for which the heavy negative ions $\sum_{j} N_{\text {seed }} Q_{\text {seed }} \ll N_{e}$, impose zero current condition

$e \sum_{i} N_{\text {seed }, j} Q_{\text {seed, } j} V_{\text {drift.seed. } j}-e \sum_{i} N_{\text {iono, },} V_{\text {drift,iono }, i}=0$

(the electrons are assumed to be collisionally coupled to the neutral atmosphere) and frictional drag one can derive the following expression for the ambipolar electric field

$E(z)=\frac{M_{N_{2}} g(z)\left[N_{\text {seed }} Q_{\text {sced }}\left(M_{\text {seed }} / M_{N_{2}}\right)-N_{\text {ion }}\left(\sigma_{\text {seed }} / \sigma_{S}\right)\right]}{e\left[N_{\text {seed }} Q_{\text {seed }}^{2}+N_{\text {lON }}\left(\sigma_{\text {seed }} / \sigma_{5}\right)\right]}$

The following parameters are used $\sigma_{\text {seed }} \sigma_{\mathrm{S}} \sim 40$ (typical elastic scattering cross-section is $\sigma_{S}=5 \times 10^{-15} \mathrm{~cm}^{2}$ for ion-neutral collisions). $N_{\text {ION }}=5000$ ions $/ \mathrm{cm}^{3}$ ( $\mathrm{HCNH}^{+}$ion), $N_{\text {seed }}=200$ anions $/ \mathrm{cm}^{3}$; $M_{\text {sced }} / M_{10 N} \sim 143\left(M_{\text {secd }}=4000 a m u\right.$, seed particle charge state $Q_{\text {seed }}=1, E(z)=0.180 \mu \mathrm{V} / \mathrm{m}, a_{\text {seed }}=e E(z) / M_{\text {seed }}-0.43 \mathrm{~cm} / \mathrm{s}^{2}<g(z)=$ $72 \mathrm{~cm} / \mathrm{s}^{2}$ at $950 \mathrm{~km}, a_{\mathrm{ION}}=e E(z) / M_{10 \mathrm{~N}} \sim 62 \mathrm{~cm} / \mathrm{s}^{2}-\mathrm{g}(z)$ at $950 \mathrm{~km}$, and then with $V_{\text {dritseed }} \sim 10 \mathrm{~m} / \mathrm{s}$ and $V_{\text {dritiono }} \sim 0.4 \mathrm{~m} / \mathrm{s}$. Using these we estimate a loss of positive ionospheric ions to the lower atmosphere by negative ions dragging them along $\sim 2 \times 10^{5}$ ions $/ \mathrm{cm}^{2} / \mathrm{s}$ (i.e., at lower altitudes they probably recombine and become part of the lower atmosphere). If, electrons were free to move vertically, they would tend to short circuit this electric field. The net effect would be to reduce the downward drag on the ionospheric ions by the heavier negative ions. This loss is not very large, and about $4 \%$ of the ionospheric wind loss from the topside ionosphere (Hartle et al., 
2008; Sittler et al., 2009). The atmospheric loss from the fall of negative ions in units of mass 28 is much larger: $\sim 5 \times 10^{6}$ ions $/ \mathrm{cm}^{2} / \mathrm{s}$ and when one combines the two losses the total ion loss $\sim 5.2 \times 10^{6}$ ions $/ \mathrm{cm}^{2} / \mathrm{s}$. This translates to a loss rate of $2.4 \times 10^{-16} \mathrm{gm} / \mathrm{cm}^{2} / \mathrm{s}$ and can be compared to a loss rate $\sim 5 \times 10^{-16} \mathrm{gm} / \mathrm{cm}^{2} / \mathrm{s}$ at $1000 \mathrm{~km}$ altitude estimated independently by Wahlund et al. (2009).

\subsection{Other observations and final comments}

\subsubsection{Fullerenes versus PAHs}

We first address the issue of fullerenes versus PAHs with the former composed only of carbon $C_{n}$, while PAHs are composed of both carbon and hydrogen $\mathrm{C}_{n} \mathrm{H}_{m}$. Hydrocarbons like $\mathrm{C}_{2} \mathrm{H}_{2}$ are considered unsaturated in hydrogen, while $\mathrm{C}_{2} \mathrm{H}_{6}$ is considered saturated. It is sometimes implied that since Titan's atmosphere is rich in hydrocarbons with relatively large amounts of hydrogen, that hydrogen poor species such as fullerenes would not form. But, in fact the reverse may be true and many experts in the study of ISM such as Thaddeus $(1994,1995)$ favored fullerenes over PAHs in an environment similar to that for Titan (i.e., low temperatures $T<150 \mathrm{~K}$ ). Observation of negative ions in the interstellar medium were primarily composed of polyyne radicals $\mathrm{C}_{2 n} \mathrm{H}^{-}$(McCarthy et al., 2006; Brünken et al., 2007; Sakai et al., 2007; Remijan et al., 2007) or unsaturated carbon nitrogen species such as $C_{3} \mathrm{~N}^{-}$ (Thaddeus et al., 2008). Vuitton et al. (2007) and later Vuitton et al. (2009b) showed significant abundances of polyynes $\left(\mathrm{C}_{2} \mathrm{H}_{2}\right.$, $\left.\mathrm{C}_{4} \mathrm{H}_{2}, \mathrm{C}_{6} \mathrm{H}_{2}, \mathrm{C}_{8} \mathrm{H}_{2}\right)$ in Titan's atmosphere at $1100 \mathrm{~km}$ using a photochemical model constrained by INMS ion measurements. In Vuitton et al. (2007) they also note that the abundance for the higher carbon chain polyynes within Titan's atmosphere did not decrease as fast as that in other photochemical models (Yung et al., 1984; Toublanc et al., 1995; Wilson and Atreya, 2004), the ISM (MacLeod et al., 1984; Remijan et al., 2006; Cernicharo et al., 2001) and/or laboratory measurements (Coll et al., 1999) as the number of carbon atoms increased in the carbon chain. It is also well known, as discussed in Thaddeus (1994, 1995) and Vuitton et al. (2007), that unsaturated polyynes can polymerize into long carbon linear chains from which fullerenes can form (Hunter, 1994; Thaddeus, 1994 , 1995). As discussed in Vuitton et al. (2007) with photodissociation making the polyyne radical $\mathrm{C}_{2 i n} \mathrm{H}_{2}+\mathrm{hv} \rightarrow \mathrm{C}_{2 n} \mathrm{H}+\mathrm{H}$ which can then react with another polyyne $\mathrm{C}_{2 n} \mathrm{H}+\mathrm{C}_{2 m} \mathrm{H}_{2} \rightarrow \mathrm{C}_{2(n+m)} \mathrm{H}_{2}+\mathrm{H}$ to make a longer carbon chain, so very long carbon chains with very small amounts of $\mathrm{H}$ can form in Titan's atmosphere. The above reactions have been confirmed both experimentally and theoretically (Smith and Rowe, 2000; Smith et al., 2006; Berteloite et al., 2008). Laboratory measurements have also shown fullerenes can form large clusters $\left(C_{60}\right)_{n}$ with index $n$ as high as $n \sim 146$ (Martin et al., 1996).

This does not mean to say that PAHs cannot also form in Titan's atmosphere since the aromatic benzene $\mathrm{C}_{6} \mathrm{H}_{6}$ and its radical phenyl $\mathrm{C}_{6} \mathrm{H}_{5}$ are present in Titan's atmosphere (Vuitton et al., 2009a and similar polymerization reaction paths may occur to make PAHs (Waite et al., 2007; Vuitton et al., 2007). As we have stated previously both processes could very well be occurring at the same time and heavier aerosols could be mixtures or conglomerations of fullerenes and PAHs (see comments by Thadoeus, 1994,1995 on large aerosol formation).

\subsection{Comment on UVIS observations of aerosols}

With regard to the UVIS observations by Liang et al. (2007) there could be a charge neutrality problem. Using Cassini Uvis stellar occultation data, Liang et al (2007) observed the haze layer down to $400 \mathrm{~km}$ altitude. Assuming a scattering radius $r_{A} \sim 12.5$ nm for aerosols, they estimated a "tholin" particle density $\sim 10^{4}$ part $/ \mathrm{cm}^{3}$ at $950 \mathrm{~km}$ and $\sim 10^{6}$ part $/ \mathrm{cm}^{3}$ at $400 \mathrm{~km}$ altitude. Such particle sizes could be in agreement with the Coates et al. (2007) heavy negative ion results if the particles are flat PAHs with radii $r_{\text {seed }}<6 \mathrm{~nm}$. Since Liang et al.'s (2007) results are not very sensitive to particle size, UVIS could also be seeing $\sim 6 \mathrm{~nm}$ size or even smaller particles. The large number of "tholin" particles observed by UVIS at $950 \mathrm{~km} \sim 10^{4}$ part $/ \mathrm{cm}^{3}$ is much greater than that observed by Coates et al. (2007) for negative ions and Waite et al. (2007) for heavy positive ions.

If a significant fraction of the haze particles observed by UVIS are charged, then we have a conflict and charge neutrality would become a serious problem when the Langmuir Probe data is also considered for which $N_{\mathrm{ec}}<5000 \mathrm{el} / \mathrm{cm}^{3}$ (Wahlund, private communication, 2009). If Coates et al. (2007) are really seeing fullerenes then they may be too small $\left(r_{\mathrm{A}}<12 \AA\right)$ for UVIS to detect and Liang et al. (2007) are seeing particles too big to be observed by CAPS-ELS. But this would not resolve the charge neutrality problem unless all the haze particles observed by UVIS are not charged. For lower mass negative ions, as modeled by Vuitton et al. (2009b) and also found in ISM the ratio $\mathrm{C}_{2 n} \mathrm{H}^{-}$ $\mathrm{C}_{2 n} \mathrm{H} \ll 1$, this ratio tends to increase with increase in the number of carbon atoms per carbon chain. Liang et al.'s (2007) results do show that the haze particles have a similar scale height to acetylene, which one might expect if the acetylene is the source of the "tholin" particles. Acetylene can polymerize and make fullerenes while benzene is probably needed to make PAHs. This would favor more fullerenes relative to PAHs.

\subsection{Entrapped oxygen in aerosols}

Using the influx rate of $\mathrm{O}^{+} \mathrm{keV}$ of $1.1 \times 10^{6} \mathrm{O} / \mathrm{cm}^{2} / \mathrm{s}$ from Hartle et al. (2006b), a seed cross-section $\sigma_{\text {seet }} \sim 4.5 \times 10^{-14} \mathrm{~cm}^{2}$ and $N_{\text {seed }} \sim 200$ ions $/ \mathrm{cm}^{3}$ an implantation rate $\sim 10^{-5}$ o implanted seed $/ \mathrm{cm}^{3} / \mathrm{s}$. The atmospheric volume needed to make one of the aerosols observed by Tomasko et al. (2005) is $\Delta V_{\text {innosphere }}-1.9 \times 10^{6} \mathrm{~cm}^{3}$, so there are $\sim 190$ atoms $/ \mathrm{s}$ implanted within each aerosol grain. If the seed particle fall rate is $\sim 3 \mathrm{~m} / \mathrm{s}$ and one uses a column density $\sim 100 \mathrm{~km}$ for $\mathrm{O}^{+}$penetration, we estimate $\sim 6.3 \times 10^{5}$ o/aerosol. One can then estimate $\sim 2 \times 10^{9}$ fullerenes per aerosol, so that there are $\sim 0.05 \%$ of the fullerenes with oxygen atoms. If one uses the medium mass flux limit by Borucki and Whitten (2008a,b) $\Phi \sim 4 \times 10^{-13} \mathrm{~kg} / \mathrm{m}^{2} / \mathrm{s}$ for the lower atmosphere one gets $\sim 6.8 \%$ of the aerosols being in the form of fullerenes. But, these are lower limits since the heavy negative ion densities and masses are expected to increase below $950 \mathrm{~km}$.

The estimated mass flux of free oxygen to the surface is then $0.1 \%$ of that incident onto the upper atmosphere from the magnetosphere, the bulk of the oxygen going to formation of $\mathrm{CO}$ and $\mathrm{CO}_{2}$.

Based on the above values for aerosol mass flux to the surface, the aerosol mass fraction from fullerenes, and fractional upper atmospheric oxygenation of the fullerenes, we estimate an oxygen mass flux to the surface of $3 \times 10^{-3} \mathrm{~kg} / \mathrm{m}^{2}$ per $300 \mathrm{Myr}$. This amounts to $7 \times 10^{-5}$ mass fraction of the one-meter aerosol layer accumulated in 300 Myr. In the same accumulation time, abiotic atmospheric oxygen production condensed to the surface on Earth, mostly from UV photolysis of atmospheric water vapor is $130 \mathrm{~kg} / \mathrm{m}^{2}$ (Chyba and Hand, 2001). For comparison, the mass fraction of photosynthetic oxygen in terrestrial sea water is $10^{-5}$ (Schlesinger, 1997).

\subsection{Heavy ions and haze generation with oxygen model}

Fig. 4 summarizes the "heavy ions and haze generation with oxygen model" as presented in this paper. The top layer signifies Saturn's magnetosphere with the exobase forming its lower 


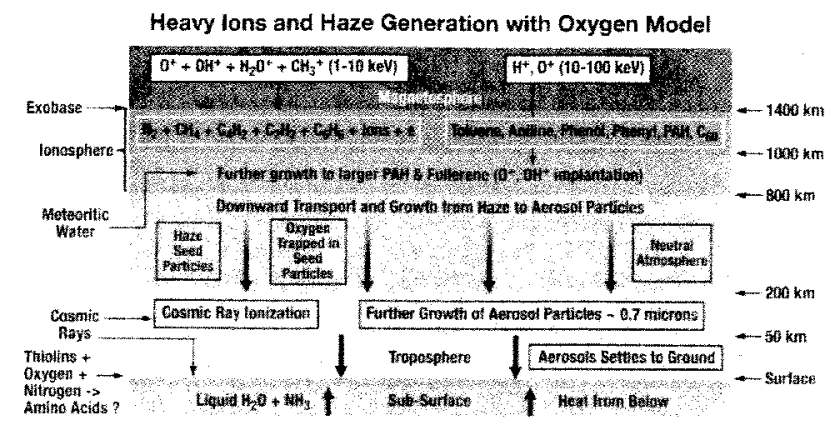

Fig. 4. Summary slide shows our "heavy ion and haze generation with oxygen model". See text for details.

boundary. The ion composition of water group ions, methane group ions with energy $1-10 \mathrm{keV}$ and more energetic $\mathrm{H}^{+}, \mathrm{O}^{+}$ions $(10-100 \mathrm{keV})$. Below the exobase lies the topside ionosphere, with lower ionosphere between 800 and $1400 \mathrm{~km}$, where the $\mathrm{keV}$ oxygen ions can become trapped with fullerenes growing along with the PAH population. Cravens et al. (2008) show that the keV $\mathrm{O}^{+}$ions deposit a significant fraction of their energy below $950 \mathrm{~km}$ altitude.

We also show cosmic rays penetrating to the lower atmosphere and meteoritic dust down to lower ionosphere. Below $950 \mathrm{~km}$ we assume further grain growth in size which then continues down to $\sim 400 \mathrm{~km}$. Below $200 \mathrm{~km}$ further growth presumably occurs at depths of maximum energy deposition from ionization by primary and secondary cosmic ray shower particles. In addition to grain growth, the cosmic rays can provide radiogenic energy to the aerosols which can then free the oxygen within the aerosols and possibly drive pre-biotic chemistry within the grains. Even after precipitation to the surface, the precipitating aerosol grains would continue to be processed chemically by irradiation from cosmic ray showers, also producing oxygen in surface or buried water ice to many meters in depth. Although height integrated cosmic ray ion production rates above $50 \mathrm{~km}$ maybe 100 times greater than that below $50 \mathrm{~km}$ (see Capone et al., 1983: MolinaCuberos et al., 1999), the time scales for descending aerosols $\sim 100-1000 \mathrm{yr}$ are much shorter than the surface irradiation times scales $\sim 30-300$ Mys (i.e., time it takes to accumulate $\sim 1 \mathrm{~m}$ of aerosols to surface). The descending aerosols may have a larger surface area for exposure than that on the surface. Therefore, cosmic rays will be effective in driving the aerosol chemistry at all phases of their time history from formation at the highest altitudes $-950 \mathrm{~km}$ down to the surface.

Borucki et al. (2006) presented evidence for ion clusters such as $\mathrm{CH}_{5}^{+} \mathrm{CH}_{4}, \mathrm{C}_{7} \mathrm{H}_{7}^{+}, \mathrm{C}_{4} \mathrm{H}_{7}^{+}$and $\mathrm{H}_{4} \mathrm{C}_{7} \mathrm{~N}^{+}$to form below $400 \mathrm{~km}$ due to the ionization of nitrogen and methane by cosmic rays. They show that PAHs, which can be electrophilic (see Bakes et al., 2002), can form negative ions and significantly reduce electron densities, between 150 and $350 \mathrm{~km}$, below that one would otherwise expect. In addition to PAHs fullerenes are also highly electrophilic as discussed previously and will similarly form negative ions. They also show that three-body electron-ion recombination collision will further reduce electron densities below expectations for heights $<60 \mathrm{~km}$ (Huygens HASI conductivity probe measurements require low electron densities as discussed in Borucki and Whitten, 2008a,b). Borucki et al. (2006) also suggest that one must consider very small aerosols called embryos which can easily be jonized and can only retain charge states $Q \sim 1$. These particles are similar in size to that observed above $950 \mathrm{~km}$ as heavy negative ions by Coates et al. (2007). Aerosol charging can contribute to atmospheric conductivities which can then be measured by the Huygens HASI instrument (see Fulchignoni et al., 2005). The haze particles then fall through the troposphere to the surface. At the surface, due to accumulation of aerosol particles we show a mixture of "tholins", oxygen, nitrogen and amino acids with the latter a speculation.

Below the surface a liquid ocean has recently been detected (Lorenz et al., 2008; Stiles et al., 2009) where interior models (Tobie et al., 2005) require ammonia as an anti-freeze since model temperatures are too low to allow pure liquid water to occur below the surface. It has been suggested that methanogenic life with this liquid ocean could be the source of Titan's methane which has a lifetime less than 100 Myrs (Fortes, 2000; McKay and Smith, 2005). This liquid water and heat, via the cryovolcanism that may have been observed (see Lopes et al., 2007; Neish et al., 2006), can then allow exobiological processes occur, especially if free oxygen is present. The observation of lakes by Cassini radar (Stofan et al., 2007), presents another tantalizing possibility for exobiological processes occurring at Titan. Recently, the Cassini VIMS experiment by Brown et al. (2008) has shown that these lakes contain ethane and are thus probably a mixture of organic molecules (see Raulin, 2008). If the aerosols discussed here do contain oxygen and land on these organic lakes a unique environment with significant astrobiological potential is created.

How important could the magnetospheric oxygen be to the astrobiological chemistry of the Titan surface and liquid subsurface environments? Over $300 \mathrm{Myr}$ we estimate an accumulated fractional mass column density of $5-6 \times 10^{-7}$ of oxygen in a onemeter aerosol layer. This ratio would presumably remain representative of the exogenic material over time as this layer is mixed deeper into the regolith by geologic and impact processes. For comparison, the mass ratio of dissolved oxygen to water is $10^{-5}$ in terrestrial sea water. This is also near the upper limits of radiolytic surface production from jovian magnetospheric interaction with the surface of Europa for downward conveyance to its putative subsurface ocean (Cooper et al., 2001). By comparison, the exogenic oxygen at Titan is not significant at the macroscopic level for the bulk chemistry of the surface as compared to Earth and possibly Europa.

On the microscopic level the astrobiological significance might be much higher if purely organic aerosol grains acquired ice shells at the surface, e.g. through water frost deposition from Enceladuslike cryovolcanic activity. The free oxygen abundance would have sources both from magnetospheric oxygen injection into the fullerenes and from direct radiolytic production in the water ice in all atmospheric and surface phases. As noted above, nitrogen and methane ions could also be implanted within the grains plus their addition to the aerosols as they fall through Titan's atmosphere. Each Titan surface grain could be a microcosm of relatively abundant organics, water ice, and free oxygen trapped in fullerenes and the water ice. Heat from impacts and volcanic activity could then initiate the pre-biotic chemistry of life in microscopic versions of Darwin's warm ponds on Titan.

\section{Acknowledgements}

This work was supported at NASA Goddard Space Flight center in part by the Cassini Plasma Spectrometer (CAPS) Project through NASA Jet Propulsion Laboratory contract 1243218 with the Southwest Research Institute in San Antonio, Texas. Additional support was provided at Goddard by the NASA Cassini Data Analysis Program (CDAP).

\section{References}

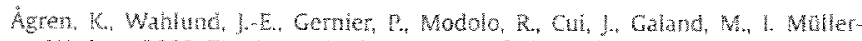
Wodarg, 20ne. The ionospheric structure of Tran, Panet Space Sci. in press. do: $10.10161,055,2009.04012$. 
Allamandola, LI. Tielens, A.G.G.M. Barker, J.R., 1989. Interstellar polycyclic aromatic hydracarbons: the infrared emission bands, the excitation/emission mechanism and the astrophysical implications. Astrophys. J. $71,733-775$.

Bakes, ELO. MciKay, C.P. Bauschlicher, C.W., 2002. Photoelectric charging of submicron aerosols and macromolecules in the Titan haze. Icarus 157, 464475 .

Berteloite, C., Le Picard, S.D., Birza, P., Gzaeau, M. C. Canosa, A., Bènilan, Y.. Sims, I.R., 2008. Low temperature (39-298 K) kinetics study of the reactions of the $\mathrm{C}_{4} \mathrm{H}$ radical with various hydrocarbons observed in Titan's atmosphere. lcarus $194,746-757$.

Bettens, R.P.A., Herbst, E., 1995. The interstellar gas phase production of highly complex hydrocarbons: construction of a model. int. I. Mass Spectrom. ion Processes 149/150, 321-343

Bohme, D.K., 1992. PAH and Fullerene ions and ion/molecule reactions in interstellar and circumstellar chemistry, Chem. Rev, 92, 1487-1508.

Borucki, W... Levin, Z., Whitten, R.C., Keesee, R.G., Capone, L.A., Summers, A.L, Toon, O.B., Dubach, 1. 1987. Predictions of the electrical conductivity and charging of the aerosols in Titan's atmosphere. Icanus 72, 604-622.

Borucki, W.J., Whitten, R.C., Bakes, E.L.O., Barth, E., Tripathi, S., 2006. Predictions of the electrical conductivities and charging of aerosols in Titan's atmosphere. lcarus $181,527-544$.

Borucki, W.I. Whitten, R.C., 2008. Influence of high abundances of aerosols on the electrical conductivity of the Titan atmosphere. Planet. Space Sci. 56, 19-26.

Bridge, H.S., et al., 1981. Plasma observations near Saturn: initial results from voyager 1 . Science 212,217 .

Broadfoot, A.L., et al., 1981. Extreme ultraviolet observations from Voyager 1encounter with Saturn. Science 212, 206.

Brown, R.H., Soderblom, LA., Soderblom, J.M., et al., 2008. The identification of liquid athane in Titan's Ontario Lacus. Nature 454, $607-610$

Brünken, S., Gupta. H., Gottlieb. C.A., MeCarthy, M.C.. Thaddeus, P., 2007. Detection of the carbon chain negative ion $\mathrm{C}_{8} \mathrm{H}^{-}$in TMC-1. Astrophys. I. 664, L43-L45.

Calcote, H.F.. Keil, D.G., 1990. Pure Appl. Chem. 62, 815.

Caldwell, K.A., Gibin, D.E., Hsu, C.S. Cox, D., Gross, M.L., 1991. Endohedral complexes of fullerene radical cations. J. Am. Chem. Soc. 113, 8519-8521.

Caldwell, K.A., Giblin, D.E., Gross, M.L., 1992. High energy collisions of fullerene radical cations with noble gases: capture of the target gas and charge stripping of $C_{50}^{*}, C_{70}^{*}$ and $C_{5,4}^{+}$J. Am. Chem. Soc. 114, 3743-3756.

Capone, L.A., Dubach. J. Prasad, S.S., Whitten, R.C., 1983. Galactic cosmic rays and $\mathrm{N}_{2}$ dissociation on Titan. Icarus $55,73-82$.

Cernicharo, J., Heras, A.M., Tielens, A.C.G.M., Pardo, J.R., Herpin, F., Guélin, M., Waters, L.B.F.M., 2001. Inftared Space Observatory's discovery of $\mathrm{C} 4 \mathrm{H} 2, \mathrm{C} 6 \mathrm{H} 2$, and benzene in CRL 618. Astrophys. ]. 546, L123-L126.

Chyba, C.F. Hand, K.P. 2001. Life without photosynthesis. Science 292, 2026-2027.

Coates, A.]. Crary, F.J., Lewis, G.R., Young, D.T., Waite Jr., J.H., Sittler Jr., E.C., 2007. Discovery of heavy negative lons in Titan's ionosphere. Geophys. Res. Lett. 34 L22103, doi: $10.1029 / 2007 \mathrm{GLO} 030978$.

Coates, A.]., Wellbrock A., Lewis, G.R., Jones, G.H., Young, D.T., Crary, F.]., Waite Jr., ].H., 2009b. Heavy negative ions in Titan's ionosphere: altitude and latitude dependence. Planet. Space Sci., in press, doi:10.1016/j.pss.2009.05.009.

Coates, A.I., 2009a. Interaction of Titan's ionosphere with Saturn's magnetosphere. Phil. Trans. R. Soc. A 367, 773-788.

Coll, P., Coscia, D., Smith, N., Gazeau, M.-C., Ramirez, S.I., Cernogora, G., Israel, G., Raulin, F, 1999. Experimental laboratory simulation of Titan's atmosphere: aerosols and gas phase. Planet. Space Sci. 47, 1331-1340.

Cooper, J.F. Johnson, R.E., Mauk, B.H., Garrett, H.B., Gehrels, N., 2001. Energetic ion and electron irradiation of the icy Galilean satellites. Icarus 149, 133-159.

Coustenis, A.r Salama, A., Lellouch, E., Encrenaz, T. Bjoraker, G.L., Sameulson, R.E. de Graauw, T., Feuchtgruber, H., Kessler, M.F., 1998. Evidence for water vapor in Titan's atmosphere from 1SO/SWS data. Astron. Astrophys. 336, L85-L89.

Cravens, T.E. Keller, CN., Ray, B. 1997. Photochemical sources of non-thermal neutrals for the exosphere of Ttan. Planet. Space Sci. 45 18),889-896.

Cravens, T.E., et al, 2006. Composition of Titan's ionosphere. Geophys. Res. Let. 33. 107105

Cravens, T.E., Robertson, IP. Ladvina, 5.A., Michell, D., Krimigis, S.M., Waite Jr. J.H., 2008. Enerctetc ion precipitation at Titan. Geophys. Res. Lett. 35, 03103 , doi: $10.1029 / 2007 \mathrm{GLO} 2451$.

Cravens. TE. et d., 2009. Model-data comparisons for Titan's nightside ionosphere. Icarus $199,174-188$.

English, M.A. Lara, LM. Lorenz, RD., Ratcli.. P. Rodrigo, R. 1996. Ablation and chemistry of meteeric materials in the amosphere of Ttan. Adv. Space Res. 17 . $157-160$.

Fortes, A. . 2000. Exobiological mplcations of a possible ammonia-water ocean instue Titan. Icants $146,444-452$

Frencliach. Wo 2002. Reaction mechanisn of soot fomation in fames. Phys. Chem Chem. Phys. 4, 2028 . 2037

Fulchignoni, M., Ferti, F, Angrilt, F, et al., 2005. In situ measurements of rive physical characteristics of Titan's environment Nature $438,785-791$.

Gerhard, th. bofler, 5, Homann, KH. 1987. Polyhedral carbon ions in hydrocarbon lames. Chem. Phys. Leth 197 , $406-310$

Coulay, F. Rebrion-Rowe, C., aries, S. Le Gartec, J., Rowe, \&R. 2004. Electron artachment on $\mathrm{H}$ and $\mathrm{DI}$ in $\mathrm{a}$ unform stpersonic flow: themahation of the ftectrons. Cham. Whe 121, 1303 .

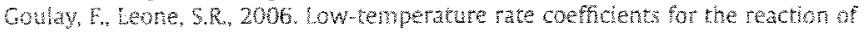
ethyny radical (CH) with berzene.]. Phys. Chem. $110(5), 1875-1880$.

Hanel, R.A. Conrath, B.J. Flasar, F.M., Kunde, V.G. Maguire, W. Peanl, I.C., Pitragha, J.A. Samueison, R, Hearth, L., Alison, M., Crukshank, D.R, Gavter, D.
Gierasch. C., Hom, L., Koppany, R., Ponnamperuma, C, 1981, Infrared observations of the Saturnian system from Voyager 1. Science $212,192-200$.

Hanel, RA., Conrath, B.J., Flasar, F.M., Kunde, V.G. Maguire, W., Pearl, J.C., Pirraglia, 1.A., Samuelson, R., Cruikshank, D.P., Gautier, D., Gierasch, P., Horn, L. Ponnamperuma, C., 1982. Infrared observations of the Saturnian system from Voyager 2 . Science $215,544-548$.

Hartle, R.E., Sittler Jr., E.C., Ogilvie, K.W. Scudder, J.D., Lazarus, A.J. Atreya. S.K. 1982. Titan's ion exosphere observed from Voyager 1. I. Geophys. Res. 87, 1383.

Hartle, R.E., Sittler Jt, E.C., Neubauer, F.M., Johnson, R.E., Smith, H.T., Crary. F. McComas, D.), Young, D.T., Coates, A. J., Simpson, D., Bolton, S., Reisenfeld, D. Szego, K., Berthelier, J.J., Rymer, A., Vilppola, J., Steinberg, J. T, Andre, N., 2006 a. Preliminary interpretation of Titan plasma interaction as observed by the Cassini plasma spectrometer: comparisons with Vayager 1. Geophys. Res. Lett. 33. L08201, doi:10.1029/2005GL024817.

Hartle, R.E. Sittler Jr., E.C., Neubauer, F.M., Johnson, R.E., Smith, H.T. Crary, F., McComas, D.j, Young. D.T., Coates, A.J, Simpson, D., Bolton, S., Reisenfeld, D. Szego, K., Bertheller, J. . Rymer, A., Vilppola, J., Steinberg. J.T., Andre, N., 2006 b Intial interpretation of Titan plasma interaction as observed by the Cassini plasma spectrometer: comparisons with Voyager 1. Panet. Space Sci, 54, 1211.

Hartle, R.E., Sittler Ir., E.C., Shappirio, M.D., Johnson, R.E., Luhmann, J.G., Ledvina, S.A. Cooper, J.F., Coates, A.J., Szego, K. Burger, M.H. Simpson, D.G., Crary. F. Young, D.T. 2006c. Satum's magnetosphere ion erosion by Titan: penetration and loss of water group ionsin upper atmosphere. EOS Trans. AGU 87 (52) Fall Meet. Suppl. Abstract 13 A-0161.

Hartle, R.E., Sittler Jr., E.C., Lipatov, A.S., 2008. Ion escape from the ionosphere of Titan, Geophys. Res. Abstr., Vol. 10, EGU2008-A-09860, 2008, SRef-ID: 1607-7962/gra/EGU2008-A 09860, EGU General Assembly.

Herbst, E., 1981. Can negative molecular ions be detected in dense interstellar clouds? Nature 289,656

Herbst, E., Osamura, $Y_{.}, 2008$. Calculations on the formation rates and mechanisms for $\mathrm{C}_{n} \mathrm{H}$ anions in interstellar and circumstellar media. Astrophys. J. 679 $1670-1679$

Hörst, S.M., Vuitton, V., Yelle, R.V., 2008. The origin of oxygen species in Titan's atmosphere. J. Geophys. Res., 113, E10006, doi:10.1029/2008JE003135.

Hunten, D.M., 1997. Titan's atmosphere and surface. In: Burns, J.A. (Ed.). Planetary Satellites. University of Arizona Press, Tucson, pp, 420-437.

Hunter, J.M., Fye, J.L., Roskamp, E.J.. Jarrold, MF., 1994. Isomerization of pure carbon cluster ions: From rings to fullerenes. In: Molecules and Grains in Space, AIP Conference Proceedings 312. Mont Sainte-Odile, France 1993, ed Iréne Nenner, pp. 571-588.

Ip. W.H., 1990. Meteoroid ablation processes in Titan's atmosphere. Nature 345, $511-512$.

Jaftke, T., Nlenberger, E., Lezius, M., Matejcik, S., Smith, D., Märk, T.D., 1994 Formation of $C_{60}$ and $C_{70}$ by free electron capture. Activation energy and effect of the internal energy on lifetime. Chem. Phys. Lett. 226, 213-218.

Johnson, R.E., Liu, M., Sittler Jr., E.C., 2005. Plasma-induced clearing and redistribution of material embedded in planetary magnetospheres. Gcophys. Res. Lett. 32, 124201, doi:10.1029/2005GL024275.

Kliore, A.J. Nagy, A.F., Marouf, E.A., French, R.G. Flasar, F.M., Rappaport, N.J. Anabttawi, A., Asmar, S.W. Kahann, D.S., Barbinis, E., Goltz, G.L., Fleischman, D.U., Rochblatt, D.J., 2008. First results from the Cassini Radio Occuitations of the Titan ionosphere. J. Geophys, Res., 113, A09317, doi:10.1029/2007JA012965.

de Kok, R., Irwin, P.G.J., Teanby, N.A., Nixon, C.A., Jennings, D. E.. Fletcher, L., Howett C. Calcutt, S.B. Bowles, N.E. Flasar, FM. Taylor, FW., 2007. Characteristics of Titan's stratospheric aerosols and condensate clouds from Cassini ClRS farinfrared spectra. lcarus 191. 223-235.

Keatschmer, W., Lamb, LD., Fostiropoulos, K., Huffman, D.R., 1990. Solid $C_{60}$ : a new form of carbon. Nature 347,354-358.

Kroto, H.W. Heath, J.R, O'Brien, S.C., Curl, R.F. Smalley, R.E, 1985. Ceo: Buckminsterfullerene. Nature 318, 162-163.

Kroto, H.W. Allaf, A.W., Balm, S.P., 1091. C6i0 : Buckminstertullerene. Chem. Rev. 91. $1213-1235$.

Kuiper, G.P. 1944. Titan: a satellite with an atmosphere. Astrophys. J. 100, 378.

Lara, LM., Lellowch, E, Lopez-Morena, J]., Rodrigo, R., 1996. Vertical distribution of Titan's atmospheric neutral constituents. 1. Geophys. Res. 101 (E10), $23261-23283$

Lavas, P. Coustenis, A. Vardavas, I.M. 2008a. Coupling photochemistry with haze formation in Titan's atmosphere: Part : Model description. Ilanet. Space Sei. $56,27-66$

Eavas. PR. Coustenis, A. Vardavas, I.M. 2008b. Coupling photochemistry with haze formation in Titan's atmosphere, Part II: Results and validaton with Cassim/Hugens data. Pinet. Space Sci. 56, $67-99$.

Lang, M-C, Yung, Y., Sherransky. D.E. 2007. Photolytically generated aerosols in the mesosphere and themosphere of Titan. Astophys. I, Lett. 6ot, $199-1202$.

lopes, R., Mitchell, K.L, Stofan, ER., et al. 2007. Cryovolcanic features on Titan's surface as revealed by the Cassint Titan Radar Mapper. lcarus 186, 395-412.

Lorenz, R.D., at al., 2008. Thtan's rotation reveals an internal ocen and changing zonal winds. Science $319,1649-1651$

Luna, H., Michael, M., Shah, M.B.. Johnson, R.E., Latimer, C. Meconkey. W. 2003.

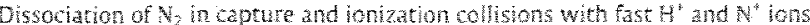
and modehng of postive ion fomator in the Titan atmosphere. S. Geophys Res. $108101029 / 2002$ J 001950

Lutz, 5 , de Bergh, C. Owen, T., 1983. Thtan: discovery of carbon monoxide in its atmosphere. Selence 220, 1374-1375 
Macleod, I.M., Avery. L.W., Broten, N.W. 1984. The detection of interstellar methyldiacetylene (CH3C4H). Astrophys. J. 282, L89-192.

Martin, T.P., Zimmermann, U., Malinowski, N., Heinebrodt, M., Frank, S., Tast. F. 1996. Clusters of fullerene molecules and metal atoms. Piys. Scr. T66, 38-47.

McCarthy, M.C., Gottlieb, C.A. Gupta, H. Thaddeus, P., 2006. Laboratory and astronomical identification of the negative molecularion $\mathrm{C}_{6} \mathrm{H}^{-}$. Astrophys. $652, \mathrm{~L} 141-1,144$

McKay, C.P., Smith. H.D. 2005. Possibilities for methanogenic life in liquid methane on the surface of Titan. Karus 178 (1) 274-276.

Mebel. A.M. Kislov, V.V., Kaiser, R.1. 2008. Photoinduced mechanism of formation and growth of polycyclic aromatic hydrocarbons in low-temperature environments via successive ethynyl radica adoitions. I. Am. Chem. Soc. 130 (41), $13618-13629$.

Michael, M., Johnson, R.E., 2005. Energy deposition of pickup ions and heating of Titan's atmosphere. Planet. Space Sc. 53, 1510-1514.

Michael, M., Johnson, R.E., Leblanc, F., Liu, M. Luhmann, I.G.. Shemantovich, V.l 2005. Ejection of nitrogen from Titan's atmosphere by magnetospheric ions and pickup ions. larus $175,263-267$.

Mille, T.]., Walsh, C. Cordiner, M.A. Ni Chumin, R, Herbse, E, 2007. Hydrocarbon anions in interstellar clouds and circumstellar envelopes. Astrophys. [. 662. 187 - 100 .

Mitchełt, D.G., Brandt, P.C., Roelof, E.C., Dandouras, J., Krimigis, S.M., Mauk, B.H., 2005. Energetic neutral atom emissions from Titan interaction with Saturn's magnetosphere. Science $308,989$.

Molina-Cuberos, G. .. Lopez-Moreno, J., Rodrigo, R., Lara, LM., O'Brien, K., 1999. Ionization by cosmic rays of the atmosphere of Titan. Planet. Space Sci. 47. $1347-1354$.

Molina-Cuberos, G.J., Lammer, H., Stumptner, W., Schwingenschuh, K. Rucker, H.O., Lopez-Moreno, J.. Rodrigo, R., Tokano, T., 2001. lonospheric layer induced by meteoric ionization in Titan's atmosphere. Planet. Space Scl. 49, 143-153.

Moustefaoui, T., Rebrion-Rowe, $C$., Le Garrec, Jean-Luc, Rowe, B.R., Mitchell, J.B.A. 1998. Low temperature electron attachment to polycyclic aromatic hydrocarbons. Faraday Discuss. 109, 71-82

Neish. C.D. Lorenz, R.D. O'Brien, D.P. 2006. The potential for prebiotic chemistry in the possible cryovolcanic dome Ganesa Macula on Titan Int I. Astrobiol 5, 57 65.

Nelson, R.M., Kamp, L.W., Matson, D.L. et al., 2009. Saturn's Titan: surface change, ammonia, and implications for atmospheric and tectonic activity. Icarus 199 $429-441$.

Ness, N.F., Acuna, M.H., Lepping, R.P. Connerney, J.E.P., Behannon, K.W., Burlaga, L.F. Neubauer, F.M, 1981. Magnetic field studies by voyager 1: preliminary results at Saturn. Science 212,211

Petrie, S., Bohme, D.K., 2007. lons in space. Mass Spectrom. Rev, 26, 258-280.

Raulin, Fo, 2008. Organic lakes on Titan. Nature 454, 587-589.

Raulin, F., Owen, T.C., 2003. Space Sci. Rev, 104, 377-394.

Remijan, A.J., Hollis, J.M., Snyder, L.E., Jewell, P.R., Lovas, F.J, 2006. Methyltriacetylene $(\mathrm{CH} 3 \mathrm{C} 6 \mathrm{H})$ toward $\mathrm{TMC}-1$ : the largest detected symmetric top. Astrophys. J. 643, L37-L40.

Remijan, A.J., Hollis, J.M., Lovas, E.J. Cordiner, M.A. Millar, T.j. Markwick-Kemper, A.J. Jewell, P.R., 2007. Detection of $\mathrm{C}_{8} \mathrm{H}^{-}$and comparison with $\mathrm{C}_{8} \mathrm{H}$ toward IRC +10 216. Astrophys. J. 664. L47-L50.

Ricca, A. Bauschlicher Jr. C.W., Bakes, E.L.O. 2001. A computational study of the mechanisms for the incorporation of a ritrogen acom into polycyclic aromatic hydrocarbons in the Titan haze. lcarus 154, 516-521.

Richter, H., Howard, J.3., 2000. Formation of polycyclic aromatic hydrocarbons and their growth to soot a review of chemical reacrion pathways. Prog. Energy Combust Sti. 26, 565-608.

Roe, H.G., de Pater, 1., Macintosh, B.A., Mckay, C.P. 2002. Titan's clouds from Gemini and Keck adaptive optics imaging. Astrophys. J. 581, 1399 1406.

Sagan, C., Khare, B.N., 1979. Tholins organic chemistry of interstellar grains and gas. Nature 277, 102-107

Sakai, N., Sakai, T. Yamamoto, 5,2007 . Detection of $\mathrm{C}_{6} \mathrm{H}$ " toward the low-mass protostar IRAS 04368+2557 in L1527. Astrophys. J, 667. L65 L68.

Sakai, N. Sakai, T. Yamamoto, S., 2008 . Tentative detection of $\mathrm{C}_{4} \mathrm{H}$ roward the low mass protostar IRAS $04368+2557$ in $L 1527$. Astrophys. $1.673,171-174$

Samuelson, R.E, Maguire, W., Hanel, R.A., Kunde, V.G., Jennings, D.E., Yung, Y.-L., Aikin, A.C., 1983. $\mathrm{CO}_{2}$ on Titan. J. Geophys. Res. $88,8709$.

Schlesinger, W.H. 1997. Biogeochemistry: An Analysis of Global Change Academic Presc San Diego p. 302.

Shah, M.B. Latimer, C., Montenegro, E.C. Tucker, O., Johnson, RE. and Smith, H.T. The implantation and interactons of $0^{\prime}$ in Titan's atmosphere; laboratory measurements of collision-induced-dissociation in $\mathrm{N}_{2}$ and the modeling of postive ion formation. Ap. (2009) in press

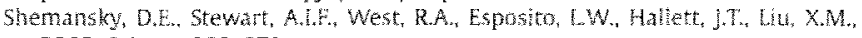
2005. Science 308,978

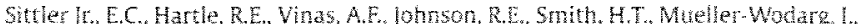
2004. Titan interaction whth Saturn's magnetosphere: mass loading and ionopause location. In: Procedings of the lntemational conterence TITAN From Discovery to Encounter, ESA Spec. Pubi. 1278, p. 377, ESTEC. Noordwik, Netherlands.

Sitter Jr, E.C, Hartle, R.E, Vinds, AF, Johnson, R, Smith, H.T, wueller-Wodarg, 2005. That interaction with satum's magnetotphere: Voyager 1 iesults revisited, 1. Geophy. Res. 110, A09302, do:101029/20041A010759

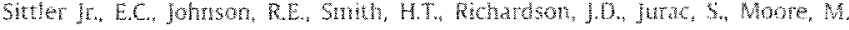

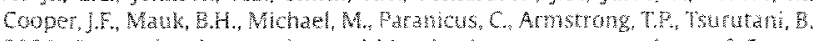
2006. Energetic nitrogen ions with the inter magnelosphere ar Satum. J. Geophys Res. 111, A09223, doi:10.1029/2004JA010509
Sittler Jt, E.C., et al., 2008. Lon and neutral sources and sinks within Saturn's inner magnetosphere: Cassini results. Planet. Space Sci 56,3-18.

Sittler Jr. E.C.. Hartle. R.E., Lipatov, A.S., Cooper, J.F., Bertucci, C. Coates, A.J., Szego, K. Johnson, R.E. Shappirio, M., Simpson, D.G., Wahlund, I.-E., 2009. Saturn's magnetospheric Interaction with Titan as defined by Cassini Encounters T9 and T18: new results. Planet. Space Sci. submitted.

Smith, D. Spanel, P. Märk, T.D. 1993. Electron attachment to $C_{60}$ at low energies. Chem. Phys. Lett. 213 (1/2), 202-206.

Snith, WM, Rowe, B.R., 2000 Reaction kinetics: at very low temperature: laboratory studies and interstellar chemistry. Acc. Chem. Res. 33 (5), 261-268.

Smith, I.W.M. Sage, AM. Donahue, N.M. Herbst. E., Quan. D., 2006. The temperatue-dependence of rapid low temperatire reactions: experiment, understanding and prediction. Faraday Discuss. 133, 137-156.

Sotin, C. Jauman, R. Buratti, B.J., et al, 2005. Release of volatiles from a possble cryovolcanio from near-infrared imaging of Titan. Nature $435,786-789$, doi: 10.1038 inature03596.

Spanel, P. Smith, D. 1994. A study of electron attachment to $C_{70}$ using the FALP technique Chem. Phys. Lett. 229, 262-266.

Spanal, P. Smith, D. 1995. Recent studies of electron attachment and electronon recombination at thermal energies. Pasma Sources Sci. Technol, 4 . $302-306$.

Srama, R., Kempf, 5., Moragas-Klostermeyer, G., Helfert, S., Ahrens, T., Aitobelli, N., Auer, S., Beckmann, U., Bradley, J.G., Button, M. Dikarev, V.V., Economou, T., Fechtig, H., Green, S.F, Grande, M. Havnes, O., Hiller, J.K., Horamyi, M., Igenbergs,

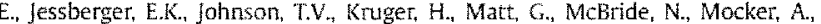
Lamy, P., Linkert, D., Linkert, G., Lura, F., McDonnell, J.A.M., Mölmann, D., Morfill, G.E., Postberg, F., Roy, M., Schwehm, G.H., Spahn, F., Svestka, J., Tschernjawski, V., Tuzzolino, A.J., Wäsch. R., Grün, E., 2006. In situ dust measurements in the inner Saturnian system. Planet. Space Sci. 54, 967-987

Stiles, B.W., Hensley, S., Gim, Y., et al., 2009. Icarus 202 (2). 584-598.

Stofan, E. R., Elachi, C., Lunine. I. I., et al. 2007. The lakes of Titan. Nature 441,6164, doi: 10.1038 /nature05438.

Thaddeus, $\mathrm{B}, 1994$. On the large organic molecules in the interstellar gas. In: tene Nenner (Ed.), Molecules and Grains in Space, AlP Conference Proceedings 312 Mont Sainte-Odile, France 1993, pp. 711-731.

Thaddeus, P., 1995. Carbon chains and the diffuse interstellar bands. In: Tielens. A.G.G.M., Snow, T.P. (Eds.). The Diffuse Interstellar Bands. Kluwer Academic Publishers, The Netherlands, pp. 369-378.

Thaddeus, P., Gottlieb, C.A., Gupta. H., Brunken, S., McCarthy, M.C., Agúndez, M. Guélin, M. Cernicharo. J., 2008. Laboratory and astronomical detection of the negative molecular ion $\mathrm{C}_{3} \mathrm{~N}^{-}$. Astrophys. $1.677,1132-1139$.

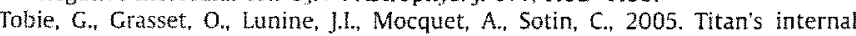
structure inferred from a coupled thermal-orbital model. Icarus 175, 496-502.

Tomasko, M., et al., 2005. Rain, winds and haze during Huygens probe's descent to Titan's surface. Nature $438(8), 765-778$

Toublanc, D., Parisot, J.P., Gautier, D., Raulin, F. Mckay, C.P. 1995. Photochemical modeling of Titan's atmosphere. Icarus 113,2.

Vuitton, V., Yelle, R.V., McEwan, M.J., 2007, lon chenistry and N-containing molecules in Titan's upper atmosphere. lcarus 191, 722.

Vuitton, V., Yelle, R.V. Lavvas, P., 2009a. Composition and chemistry of Titan's thermosphere and ionosphere. Phil. Trans. R. 5oc. A 367, 729-741.

Vuitton, V., Lavvas, P., Yelle, R.V., Galand, M., Wellbrock, A., Lewis, G.R., Coates, A.J. Wahlund, J.-E., 2009b. Negative ion chemistry in Titan's upper atmosphere [lanet. Space Sci. in press, doi:10.1016/j.pss.2009.04.004

Wahlund, J.-Ex, et al. 2005. Cassini measurements of cold plasma in the ionosphere of Titan. Science 308, 986-989

Wahlund, J.-E., Galand, M. Muller-Wodarg, L. Cui, J., Yelle, R.V., Crary, F. ., Mandth K., Magee, B., Waite Jr. J.H., Young, D.T., Coates, A.J., Garnier, P., Agren, K., Andre M. Eriksson, A... Cravens, T.E., Vuitton, V., Gumett D.A., Kurth, W. 2009. On the amount of heavy molecular ions in Titan's ionosphere. Planet. Space Sci., in press, doi: $10.1016 /$ i.pss.2009.07.014.

Wate, JH, et al, 2005 . Ion neutral mass spectrometer results from the first flyby of Titan. Science 308, 982-986.

Wate J., I.H. Young, D.T., Cravens, T.E., Coates, A.J., Crary. F. . Magee, B., Westlake 1, 2007. The process of Tholin formation in Titan's upper atmosphere. Science 316,870 , doi:10.1126/science 1139727 .

Waite J., J.H. Young, D.T. Coates, A.I., Crary, F, Magee, B.A., Mand, KE. Westlake, J.H. 2008. The Source of Heavy Orgabics and Aerogols in Than's Antosphere 2008, Aut: Organc Matter in Space, WN Symposium and colloquin procedings series, no. 251 , pp. $321-326$.

Wang, 1.5. Conceica, 1. In, 1. Smalley, R.E. 1991. Theshold photoderahment of

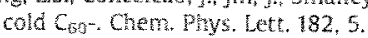

Wang, X. Woo, H.K., Wamg L.5. 2005. Vibratond coolng in a cold ion trap: Vibrationaly resolved photoelectron spectroscopy of cold Go anons, J. Chem Phys. 123, 051106, doi:10.1063/1998787.

Weiske, T. Bohme, D.k. Schwar2, H. 1991. Injection of helum atons into doubly and triply charged $C_{60}$ cations. I. Phys. Chem. 95, 8451-8452.

Wison, E.H., Atrey, SK. 2004. Current state of modeling the photochemistry of Than's mutualy dependent atmosphete and ionosphere. I. Geophys. Res. 109 , E06002, doi: $101029 / 2003$ E002181.

Yang, S.H. Pertiette, CL. Concelcro, J. Chesmovsky, O. Smalley, R.E. 1987. Chem Phys. Lett. $139,233$.

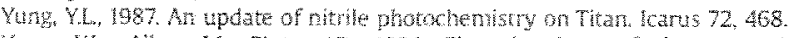

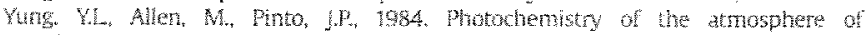
Than: comparison between model and ohserators. Astrophys. J. Suppl 55, 465 